Future Neurol. 2009 July 1; 4(4): 449-467. doi:10.2217/fnl.09.17.

\title{
Transglutaminase activation in neurodegenerative diseases
}

\author{
Thomas M Jeitner ${ }^{\dagger}$, \\ Applied Bench Core, Winthrop University Hospital, 222 Station Plaza North, Suite 502, Mineola, NY \\ 11501, USA Tel.: +1 5166633455 Fax: +1 5166633456 tjeitner@winthrop.org \\ Nancy A Muma, \\ Department of Pharmacology \& Toxicology, School of Pharmacy, University of Kansas, 1251 \\ Wescoe Hall Drive, 5064 Malott Hall, Lawrence, KS 66045, USA Tel.: +1 7858644002 Fax: +1 785 \\ 8645219 nmuma@ku.edu
}

Kevin P Battaile, and

IMCA-CAT, University of Chicago, 9700 S. Cass Ave, Bldg 435A, Argonne, IL 60439, USA Tel.: +1 6302520529 Fax: +1 6302520521 battaile@anl.gov

\author{
Arthur JL Cooper \\ Department of Biochemistry \& Molecular Biology, New York Medical College, Valhalla, NY 10595, \\ USA Tel.: +1 9145943330 Fax: +1 9145944058 arthur_cooper@nymc.edu
}

\begin{abstract}
The following review examines the role of calcium in promoting the in vitro and in vivo activation of transglutaminases in neurodegenerative disorders. Diseases such as Alzheimer's disease, Parkinson's disease and Huntington's disease exhibit increased transglutaminase activity and rises in intracellular calcium concentrations, which may be related. The aberrant activation of transglutaminase by calcium is thought to give rise to a variety of pathological moieties in these diseases, and the inhibition has been shown to have therapeutic benefit in animal and cellular models of neurodegeneration. Given the potential clinical relevance of transglutaminase inhibitors, we have also reviewed the recent development of such compounds.
\end{abstract}

\section{Keywords}

Alzheimer's disease; calcium; Huntington's disease; neurodegeneration; Parkinson's disease; transglutaminase

\begin{abstract}
Transglutaminases (TGs) catalyze various modifications of glutaminyl (Q) residues including covalent intra- and inter-molecular crosslinking with lysyl (K) residues. The activity of these enzymes and the products thereof are markedly increased in a variety of neurodegenerative disorders. Moreover, proteins thought to be pathogenic in these diseases are often TG substrates. Despite these findings, there is ambiguity concerning the role that TGs play in disorders, such as Alzheimer's disease (AD), Parkinson's disease (PD) or Huntington's disease (HD), and of the therapeutic benefit of inhibiting TG activity in these disorders. This ambiguity is partly due to questions concerning the activation of these enzymes in vivo. Depending on the TG, these enzymes are activated by a combination of proteolysis and $\mathrm{Ca}^{2+}$ or $\mathrm{Ca}^{2+}$ alone, and inhibited by GTP. Although little is known regarding the levels of cerebral GTP in
\end{abstract}

(C) 2009 Future Medicine Ltd

†Author for correspondence: Applied Bench Core, Winthrop University Hospital, 222 Station Plaza North, Suite 502, Mineola, NY 11501, USA Tel.: +1 5166633455 Fax: +1 5166633456 tjeitner@ winthrop.org. 
neurodegenerative disorders, increases in intracellular $\mathrm{Ca}^{2+}\left(\mathrm{Ca}^{2+}{ }_{i}\right)$ are recognized to be an important, if not essential, factor in the etiology of neurological diseases. Given the propensity of disease-specific increases in $\mathrm{Ca}^{2+}{ }_{i}$ to stimulate in vivo TG activity, we have sought to review the activation of TGs by this cation in both in vitro and neuropathological contexts to better understand the involvement of these enzymes in pathologies such as AD, PD and HD. Since TGs are likely to contribute to these diseases we have also reviewed recent developments in the search for selective TG inhibitors.

\section{Cerebral TGs \& Y-glutamylamine formation}

The brain expresses at least four of the eight active TGs produced by mammals, namely TGs $1-3$ [1-3] and 6 [4]. TGs catalyze a variety of modifications of the carboxamide moiety [-C (O) $\mathrm{NH}_{2}$ ] of $\mathrm{Q}$ residues, including transamidation [5], deamidation [6,7] and esterification [8], in which the carboxamide moiety is modified to $[-\mathrm{C}(\mathrm{O}) \mathrm{NHR}],\left[-\mathrm{CO}_{2}^{-}\right]$and $[-\mathrm{C}(\mathrm{O}) \mathrm{OR}]$, respectively. Even so, the only reaction attributed to cerebral TGs thus far is transamidation. This reaction converts the carboxamide moiety of a $Q$ residue to a substituted carboxamide using amine-bearing compounds such as monoamines, diamines, polyamines and $\mathrm{K}$ residues as attacking nucleophiles [5]. Of the possible reaction products, the $\gamma$-glutamyl-e-lysine [ $N^{\varepsilon}$ $(\gamma$-L-glutamyl)-L-lysine] isopeptide linkage formed between the $\mathrm{Q}$ and $\mathrm{K}$ residues, is the most commonly studied. This bond can be formed both within and between polypeptide chains. The placement of $\gamma$-glutamyl- $\varepsilon$-lysine linkages between polypeptides may result in protein aggregation. Since the deposition of multimeric structures is a common feature of neurodegenerative disorders, the formation of $\gamma$-glutamyl- $\varepsilon$-lysine bonds and the inhibition thereof has attracted much interest. TGs can also crosslink polypeptides with $b i s-\gamma-$ glutamylpolyamine bridges $[9,10]$. These bridges are formed by two successive transamidations, the first of which involves the attack of a polyamine on a $\mathrm{Q}$ residue to generate a $\gamma$-glutamylpolyamine residue. This moiety has a free terminal amine allowing it to participate in a second transamidation and thereby produce a $b i s-\gamma$-glutamylpolyamine linkage. $\gamma$ Glutamylamines are excised unaltered during proteolysis and the amount of these freed molecules reflects in situ TG activity [11-13]. Based on such measurements, bis- $\gamma$ glutamylputrescine crosslinks appear to be formed at least as frequently as $\gamma$-glutamyl- $\varepsilon$-lysine isopeptide linkages [11]. Of the free $\gamma$-glutamylamines thus far identified in human cerebrospinal fluid (CSF; i.e., $\gamma$-glutamylspermidine, $b i s-\gamma$-glutamylputrescine, $\gamma$-glutamyl- $\varepsilon$ lysine and bis- $\gamma$-glutamylputrescine), $\gamma$-glutamylspermidine at a concentration of $670 \mathrm{nM}$, is the most prevalent [11]. The concentration of bis- $\gamma$-glutamylputrescine in CSF exceeds that of $\gamma$-glutamylputrescine by approximately sixfold (i.e., $242 \mathrm{vs} 39 \mathrm{nM}$ ). If the concentration of bis- $\gamma$-glutamylspermidine similarly exceeds that of $\gamma$-glutamylspermidine then bis- $\gamma$ glutamylpolyamine bonds would represent the predominant crosslink formed by TGs in the brain.

Recent studies suggest that some proteins crosslinked by $\gamma$-glutamyl- $\varepsilon$-lysine bridges may be relatively soluble $[14,15]$. In one study, a thioredoxin fusion protein containing a $\mathrm{Q}_{65}$ domain spontaneously formed noncovalent insoluble aggregates [14]. In the presence of TG 2, soluble high-molecular-weight polymers were obtained. However, inhibition of $\gamma$-glutamyl- $\varepsilon$-lysine crosslink formation by putrescine or by 5-biotin amidopentylamine antagonized the ability of TG 2 to form soluble high-molecular-weight polymers [14]. The antagonism by putrescine is presumed to be the result of covalent formation of $\gamma$-glutamylpolyamine linkages. These studies suggest that endogenous polyamines may modulate the formation of TG-catalyzed soluble aggregates. Despite these observations, little is known regarding the levels of either $\gamma$ glutamylpolyamines or bis- $\gamma$-glutamylpolyamines in the brain and much less is known regarding the proteins in which these crosslinked species are present. 
The ability to infer observations about in situ TG activity from the levels of free $\gamma$ glutamylamines derives from a novel aspect of the TG reaction. $\gamma$-Glutamylamine bonds are resistant to the action of proteases. Consequently, $\gamma$-glutamylamines are excised intact when proteins containing these residues are degraded by proteolysis. The amide bond in free $\gamma$ glutamylamines can be cleaved by $\gamma$-glutamylamine cyclotransferase to produce free amine and 5-oxoproline. However, the activity of this enzyme in brain is low [16] and we have suggested that levels of free $\gamma$-glutamylamines are a good surrogate for in vivo TG activity in brain [11-13]. The resistance of the $\gamma$-glutamylpolyamine bonds to proteolysis suggests a novel permanent alteration of proteins. Polyamination increases the activity of a number of enzymes [17-19], notably phospholipase $A_{2}$. In the case of phospholipase $A_{2}$, the covalent attachment of polyamines causes a threefold increase in specific activity [17]. If this change persists for the life of this enzyme then it would represent a profound change in overall lipase activity. This is in stark contrast to the transient nature of some other post-translation modifications that affect enzymatic activity (e.g., phosphorylation), which typically last from seconds to minutes depending on the substrates. Thus, polyamination has the potential to bring about global and persistent changes in cellular metabolism. Such changes may herald crucial progressions in disease etiology. For example, the polyamination of phospholipase $A_{2}$ would significantly increase the production of leukotrienes and prostaglandins and by this mechanism could contribute to the inflammation associated with many neurodegenerative disorders.

\section{$\mathrm{Ca}^{2+} \& \mathrm{TG}$ activation}

$\mathrm{Ca}^{2+}$ is absolutely required for the activation of the well-studied TGs [20]. Moreover, the full activation of these enzymes in most in vitro assays requires millimolar concentrations of $\mathrm{Ca}^{2+}$. Mammalian blood and interstitial fluid contain millimolar amounts of $\mathrm{Ca}^{2+}$ capable of activating extracellular TG 2 and factor XIII, and do so as indicated by the presence of $\gamma$ glutamylamine linkages in extracellular matrices, cell envelopes and blood clots [21,22]. Blood clots in the horseshoe crab also contain crosslinked proteins [23]. With the exception of those in the outer epidermis, cells typically maintain basal concentrations of cytosolic $\mathrm{Ca}^{2+}$ between 20 and $100 \mathrm{nM}$ and allow increases of up to $500 \mathrm{nM}$ following cellular activation [24]. This range of permittable $\mathrm{Ca}^{2+}{ }_{i}$ concentrations raises the question of how the intracellular TGs are activated. TGs are clearly activated within cells as evidenced by the presence of $\gamma$ glutamylamine bonds in cellular proteins [10] and the demonstration of polyamination in cellbased models $[25,26]$. The tertiary structures of TGs $1-3$ have been resolved and indicate the presence of three conserved $\mathrm{Ca}^{2+}$-binding sites on these enzymes [27-32]. Unfortunately, these studies have not suggested a mechanism for the full activation of TGs at cytosolic $\mathrm{Ca}^{2+}$ concentrations. Nonetheless, the known locations of the three $\mathrm{TG} \mathrm{Ca}^{2+}$-binding sites have provided valuable insights into the catalysis of transamidation.

Despite limited sequence homology (e.g., TG 2 and 3 share $40 \%$ identity) [27,28], TGs conform to a common architecture of four contiguous ellipsoidal domains: an $\mathrm{N}$-terminal $\beta$ sandwich followed by a catalytic core, and then two C-terminal $\beta$ barrels. A hinge region (Leu ${ }^{312}$ $\mathrm{Arg}^{317}$ in TG 2) connects the catalytic core domain to the first $\beta$ barrel and facilitates the occupation of at least two conformational states: closed and open [32]. In the closed state, the hinge region resembles a $\beta$ strand and allows the $\beta$ barrels to drape across the active site and prevent substrate access (Figure 1). Enzyme activation causes the hinge region to conform to an $\alpha$ helix, which in turn forces the domains into an open conformation exposing the active site (Figure 2). This movement displaces the $\beta$ barrels by as much as $120 \AA$ and represents a substantial conformational change. The demonstration of these conformational states has been of particular importance, as it has revealed for the first time how two protein TG substrates might interact simultaneously with the catalytic core [32]. 
An interesting hypothesis to account for the conversion of the hinge region from a $\beta$ strand to an $\alpha$ helix invokes a prolyl cis-trans isomerization to power the change. Transition between the cis and trans conformations require a $180^{\circ}$ change in the orientation of the prolyl bond and as such can produce profound effects in protein secondary structure [33,34]. TGs 1-3 contain a cis prolyl bond in the hinge region $\left(\mathrm{Gly}^{472}-\mathrm{Pro}^{473}\right.$ in TG 3 ) and, therefore, isomerization of this bond may be sufficient to induce the hinge $\beta$-strand to assume an $\alpha$-helical conformation $[28,31]$. This type of mechanism has successfully accounted for the conformational changes of other multidomain proteins [35]. Investigations of prolyl cis-trans isomerizations in proteins usually require nuclear magnetic resonance (NMR)-based techniques [36]. However, the structures of TGs 1-3 are too large to be resolved by current NMR methods. Other tests for the involvement of prolyl isomerization could involve mutation of the $\mathrm{Pro}^{473}$ residue and NMRbased conformational studies of the TG catalytic core domain bound only to the nearest $\beta$ barrel via the hinge region. Ahvazi and coworkers [31] have pointed out that prolyl isomerization may occur at too slow a rate to account for the kinetics of TG-catalyzed reactions (the activation energy of prolyl isomerization is $\sim 20 \mathrm{kcal} / \mathrm{mol}$ ) [33]. Indeed, prolyl isomerization may account for the lag period commonly observed in assays of TG kinetic activity. Prolyl isomerases significantly increase the rate of isomerization [34] and may act in concert with TGs to catalyze transamidation in vivo. This hypothesis could be readily tested by an investigation of the effect of prolyl isomerases on the kinetics of TG reactions.

Cis peptide bonds are metastable and are kept in place by extensive hydrogen bonding and hydrophobic side chain interactions. Disruption of these stabilizing forces favors prolyl cistrans isomerization. However, the $\mathrm{TG} \mathrm{Ca}^{2+}$-binding sites are not sufficiently close to the hinge cis prolyl bond to directly impinge on its chemical environment [30]. Nonetheless, $\mathrm{Ca}^{2+}{ }_{-}$ induced conformational alterations in the neighboring catalytic core may affect the cis-trans isomerization of the $\mathrm{Gly}^{472}-\mathrm{Pro}^{473}$ peptide bond. $\mathrm{Ca}^{2+}$ binds at three highly conserved sites within the catalytic core domain of TGs $1-3[30,31,37]$. Site 1 in TG 3 is defined by $\mathrm{Ala}^{221}$, $\mathrm{Asn}^{224}, \mathrm{Asn}^{226}$ and $\mathrm{Asp}^{228}$ (Figure 3) and binds $\mathrm{Ca}^{2+}$ with an affinity of $0.3 \mu \mathrm{M}$. This tight binding suggests that the $\mathrm{Ca}^{2+}$ at site 1 is essentially permanently bound to the enzyme and acts to stabilize the local structure [30]. $\mathrm{Ca}^{2+}$ binds to sites $2\left(\mathrm{Asn}^{393}, \mathrm{Ser}^{415}, \mathrm{Glu}^{443}\right.$ and $\mathrm{Glu}^{448}$; Figure 4) and $3\left(\mathrm{Asp}^{301}, \mathrm{Asp}^{303}, \mathrm{Asn}^{305}, \mathrm{Ser}^{307}\right.$ and $\mathrm{Asp}^{324}$;Figure 5) with a lower average affinity of $3 \mu \mathrm{M}$ and can dissociate from the enzyme. The binding of $\mathrm{Ca}^{2+}$ to sites 2 and 3 causes large conformational changes in TG $[28,30]$. Sites 2 and 3 are also in close proximity to cis peptide bonds between $\mathrm{Pro}^{372}-\mathrm{Tyr}^{373}$ and $\mathrm{Gly}^{472}-\mathrm{Lys}^{488}$ and, therefore, $\mathrm{Ca}^{2+}$ binding may induce the cis-trans isomerization of these bonds. $\mathrm{Pro}^{372}-\mathrm{Tyr}^{373}$ and Gly ${ }^{472}$-Lys ${ }^{488}$ peptide bond isomerization may, in turn, alter the conformation of the hinge Gly $^{472}-$ Pro $^{473}$ peptide bond and displace the $\beta$ barrels from the catalytic core.

The binding of two $\mathrm{Ca}^{2+}$ ions (given that one $\mathrm{Ca}^{2+}$ is permanently associated with site 1) to the catalytic core domain induces TG 2 to adopt an open conformation exposing the substrate binding sites and the catalytic residues [32]. Q-bearing substrates typically containing sequences $\mathrm{QxP} \phi \mathrm{D}(\mathrm{P}), \mathrm{QxP} \phi$ or $\mathrm{Qxx} \phi \mathrm{DP}$ (where $\phi$ represents hydrophobic amino acids) [38], bind to a hydrophobic pocket consisting of $\mathrm{Ala}^{304}, \mathrm{Leu}^{312}, \mathrm{Ile}^{313}, \mathrm{Phe}^{316}, \mathrm{Ile}^{331}$ and $\mathrm{Leu}^{420}$ in the TG 2 catalytic core [32]. The conformational changes that allow substrate binding also juxtapose $\mathrm{Cys}^{277}$ to $\operatorname{Trp}^{241}$, which then form a thiolate-imidazolium ion pair oriented by $\mathrm{Asp}^{358}$. These changes allow a nucleophilic attack by the thiolate ion on the electron-deficient carbonyl of the $\gamma$ carboxyamine group to generate an oxyanion intermediate [39]. The charge on the oxyanion is stabilized by hydrogen bonding with the backbone nitrogen of $\mathrm{Cys}^{277}$ and $\mathrm{N}^{\varepsilon} 1$ nitrogen of Try ${ }^{241}$. Subsequent acylation results in the release of $\mathrm{NH}_{3}$ and the formation of an acyl-enzyme intermediate. The amine-bearing substrate then approaches the acylated Cys ${ }^{277}$ via a tunnel roofed by $\operatorname{Typ}^{241}$ and $\operatorname{Trp}^{332}$ and guided by $\operatorname{Try}^{360}[32,39]$. Nucleophilic attack by the amine group leads to the formation of a second oxyanion, again stabilized by hydrogen bonding with Cys ${ }^{277}$ and Try ${ }^{241}$. Deacylation then completes the reaction. 
The key residues and structural motifs cited above are conserved among TGs 1-3 and make it likely that the aforementioned reaction scheme is shared by these enzymes. Thus, 'dormant' TG exists in a closed conformational state in which the $\beta$ barrels obscure the catalytic core. This self- or auto-inhibition is relieved by $\mathrm{Ca}^{2+}$ binding to two sites in the catalytic core, causing the $\beta$-barrels to be displaced in such a manner as to expose the catalytic quartet of $\mathrm{Asp}^{358}$, $\mathrm{His}^{335}$, $\mathrm{Cys}^{277}$ and $\operatorname{Trp}^{241}$ (in TG 2) and allow the binding of up to two protein substrates. The substrate Q residue undergoes a nucleophilic attack by the activated thiolate of $\mathrm{Cys}^{277}$ to generate an acyl intermediate, which in turn undergoes a nucleophilic attack by an aminebearing substrate. Subsequent deacylation releases the substrate bearing an amide-substituted $\mathrm{Q}$ residue.

Equilibrium dialysis studies have established that $\mathrm{Ca}^{2+}$ binds TG 3 at micromolar concentrations $[28,30]$, so why are millimolar amounts of $\mathrm{Ca}^{2+}$ required to activate these enzymes in vitro? This is an important question, since in the absence of an adequate explanation it has been suggested that TGs are rarely activated in some in vivo situations. These suggestions ignore both the presence of these enzymes within cells and the presence of $\gamma$-glutamyl linkages in the body. The explanation probably resides with the choice of Q-bearing substrates chosen for in vitro TG assays. Casein (or $N, N$-dimethylcasein) is commonly used to assay TG activity. This protein is typically extracted in a phosphate buffer and consequently has a high content of covalently bound phosphate [40]. As noted earlier, the binding site for Q-bearing substrates in TG 1-3 is a hydrophobic pocket. The charge imparted by phosphate could interfere with the binding of casein to TG. $\mathrm{Ca}^{2+}$ readily binds and neutralizes the charge on phosphate and this neutralization may account for the millimolar $\mathrm{Ca}^{2+}$ requirement in TG assays. Indeed, the $K_{\mathrm{m}}$ of TG 2 for $\mathrm{Ca}^{2+}$ becomes $3-4 \mu \mathrm{M}$ when dephosphorylated, rather than phosphorylated, casein is used as substrate in in vitro assays [41]. These observations and those demonstrating the formation of $\gamma$-glutamylamine linkages in situ indicate that TGs can be, and are, activated by physiological levels of $\mathrm{Ca}^{2+}{ }_{i}$ concentrations.

The activation of TG 2 by $\mathrm{Ca}^{2+}$ is attenuated by GTP [25,29]. TG 1 also contains a guanosinebinding site but its ability to catalyze transamidation is not inhibited by GTP [31]. While $\mathrm{Ca}^{2+}$ has little effect on the binding of GTP to TG 2, it does lower the rate of GTP hydrolysis by this enzyme [31]. GTP induces conformational changes in TG 2, but how these changes might affect $\mathrm{Ca}^{2+}$ binding to sites 1,2 or 3 is unknown. Unfortunately, very little is known regarding guanosine nucleotide concentrations in the brain, making it difficult to evaluate the role of GTP binding and hydrolysis in the regulation of cerebral TGs.

\section{Overview of $\mathrm{Ca}^{2+}{ }_{i}$ homeostasis in the brain}

An approximately 10,000-fold differential exists between the extra- $(\sim 1-2 \mathrm{mM})$ and intra- (50 $-100 \mathrm{nM}$ ) cellular pools of $\mathrm{Ca}^{2+}$. Since this gradient is so great the plasma membrane channel responsible for $\mathrm{Ca}^{2+}$ entry into cells only allows small amounts of this ion to access the cytosol at any time. This $\mathrm{Ca}^{2+}$ signal is subsequently amplified by $\mathrm{Ca}^{2+}$ release from the endoplasmic reticulum (ER) via two channels: the inositoltrisphosphate $\left(\mathrm{IP}_{3}\right)$-responsive channel and the ryanodine receptor (RyR). $\mathrm{IP}_{3}$ is often cleaved from phosphatidylinositol 4,5-bisphosphate $\left(\mathrm{PIP}_{2}\right)$ in conjunction with the opening of plasmalemmal $\mathrm{Ca}^{2+}$ channels. The release of $\mathrm{Ca}^{2+}$ from the ER via $\mathrm{IP}_{3}$-channels causes an increase in $\mathrm{Ca}^{2+}{ }_{i}$, which in turn, signals additional $\mathrm{Ca}^{2+}$ release from the ER via the RyR. These elevations in $\mathrm{Ca}^{2+}$ concentrations are countered by ATP-dependent $\mathrm{Ca}^{2+}$ pumps, which operate to either expel $\mathrm{Ca}^{2+}$ from the cell or to sequester it within mitochondria or the ER. Schematically, these processes can be represented as:

Plasma membrane channels $(+) \rightarrow \mathrm{IP}_{3}$-responsive channels $(++) \rightarrow$ RyR $(++++) \rightarrow$ ATPdependent $\mathrm{Ca}^{2+}$ pumps (-). 
The positive and negative signs (shown in parentheses) represent the net effect of these channels and pumps on $\mathrm{Ca}^{2+}{ }_{i}$ concentrations.

\section{AD: features \& hypotheses}

The most common form of dementia affecting humans is $\mathrm{AD}$, which manifests as progressive memory loss and cognitive decline. In most cases, these manifestations of AD appear after 65 years of age and are a harbinger of death. AD primarily affects the pyramidal neurons of the hippocampus and is distinguished by an excessive deposition of amyloid plaques and neurofibrillary tangles in the cerebral cortex [42]. Plaques are external to neurons and are comprised of insoluble aggregates of amyloid $\beta(\mathrm{A} \beta)$ and other proteins, whereas tangles are intracellular aggregates of hyperphosphorylated tau and other cytoskeletal elements. When $\mathrm{AD}$ was first described in 1906, a relatively small percentage of adults survived beyond 60 years of age or more, and consequently, the incidence of this disease was thought to be sporadic. With the marked increase in life expectancy over the last 100 years, AD has been revealed to be a frequent cause of death among the elderly. The risk factors for AD include advanced age, poor diet, diabetes, hypertension, head trauma and inheritance of the $\varepsilon 4$ allele of the apolipoprotein E [42]. Specific mutations in the genes for A $\beta$ precursor protein (APP), presenilin 1 or presenilin 2, result in a rare and early-onset form of the disease known as familial $\mathrm{AD}[43]$.

Two leading hypotheses have been put forward to account for the development of AD. The first of these - the amyloid hypothesis - posits that $A \beta$ deposits initiate the disease [44]. This hypothesis is supported by several observations. The APP gene resides on chromosome 21 . Consequently, trisomy 21 (Down syndrome) sufferers have three copies of this gene and invariably develop AD by 40 years of age [45]. Moreover, inheritance of the apolipoprotein E $\varepsilon 4$ allele leads to an excessive accumulation of cerebral $A \beta$-containing plaques, the deposition of which precedes the behavioral changes associated with this disease. However, a number of observations concerning A $\beta$-containing plaques are not consistent with the amyloid hypothesis. For example, plaque distribution is not coincident with the histological pattern of damage in $\mathrm{AD}$, and ridding the brain of plaques with antibodies does not resolve the disease in humans [46]. Moreover, in a mouse model of AD there is no close correlation between neuronal loss and plaque formation [47]. The other major hypothesis to account for the development of $\mathrm{AD}$ - the tau hypothesis - contends that neurofibrillary tangles primarily cause this disease [48].

\section{TG expression \& activity in AD}

Transglutaminase activity is significantly increased in the affected regions of AD brain [1, 49] and TG 1, TG 2 and $\gamma$-glutamyl-e-lysine are present in pathological lesions in AD brain $[3,50]$. An increase in the amount of $\gamma$-glutamyl- $\varepsilon$-lysine crosslinked proteins in insoluble protein in AD brain was shown previously [1]. TG 1 and TG 2 protein expression is increased in AD brain [1], which presumably accounts at least in part for the increased TG activity in $\mathrm{AD}$ brain. Many studies have focused on the expression of TG 1 in skin, where the enzyme is regulated via AP1 and Sp1-binding sites [51], but the factors regulating the expression of TG 1 in brain have not been identified. The TG 2 promoter contains an NF- $\kappa \beta$-binding site through which glutamate and inflammatory mediators have been shown to act [52-56], and both glutamate excitotoxicity and inflammation are thought to contribute to AD. An alternatively spliced truncated variant of the TG 2 message, termed 'short TG 2', is also generated in brains of AD patients [57]. Short TG 2 expression may be particularly important in the later stages of AD. Truncated TG 2 lacks the ability to bind GTP and promotes apoptosis in vivo independently of the transamidation reaction [58].

$\gamma$-Glutamyl- $\varepsilon$-lysine immunoreactivity co-localizes with $A \beta$ in senile plaques in AD brain [3]. For TG 2 to catalyze $\gamma$-glutamyl-e-lysine crosslinks in these plaques, the enzyme would 
require release from neurons. However, to the best of our knowledge, the export of TGs from neurons has not been demonstrated. Nevertheless, TG 2 is present in CSF and in a greater amount in $\mathrm{AD}[59]$ and $\mathrm{PD}$ patients [60]. The most likely source for this activity is the brain. However, it should be noted that the activity could result either from cellular export (as shown, for example, for endothelial and epithelial cells of noncerebral origin [61-63]) or from cell lysis. Siegel et al. [64] have reported that extracellular TG 2 is catalytically inactive, but is transiently activated upon tissue injury. However, other studies suggest that TG exported to the extracellular environment is a ctivated by $\mathrm{Ca}^{2+}[61-63]$.

Amyloid $\beta$ [65-67] and A $\beta$ bearing the Dutch mutation (Q22 $\rightarrow$ E22) [66] are in vitro substrates of TG2. The resulting polymers resemble the aggregates seen in AD brain, and it has been suggested that TGs contribute to AD by initiating $A \beta$ oligomerization and aggregation at physiological levels [67]. Adballa et al. [68,69] demonstrated that the formation of A $\beta$ leads to oxidation of tyrosine residues of neighboring Ang II receptors $\left(\mathrm{AT}_{2}\right)$ causing these proteins to dimerize. The dimerized proteins are then substrates for further oligomerization by TGs. Ang II $\mathrm{AT}_{2}$ oligomers sequester the $\mathrm{G} \alpha_{\mathrm{q} / 11} \mathrm{G}$ protein, inhibiting its activity, and cause a phenotype reminiscent of $\mathrm{AD}$. The notion that TG-catalyzed aggregation causes pathology by removing critical proteins has been proposed earlier. For example, glyceraldehyde 3-phosphate dehydrogenase, $\alpha$-ketoglutarate dehydrogenase complex and histones [70-72] are in vitro TG substrates whose loss or covalent modification might compromise normal cell functioning. Crosslinking of ubiquitin, HSP27, parkin and $\alpha$-synuclein by $\gamma$-glutamyl- $\varepsilon$-lysine bonds in Alzheimer's neurofibrillary tangles has been detected in AD brain [73]. Crosslinking of tau was not detected in these studies (however, see below).

Transglutaminases may play a significant role in the stabilization of neurofibrillary tangles. $\gamma$-Glutamyl-e-lysine bonds have been identified within tangles $[2,3,50,65]$ and the proteins that comprise these structures are in vitro TG 2 substrates. These proteins include tau [26,50, 74-79] and $\alpha$-synuclein [65,80-82]. The actions of TG on $\alpha$-synuclein will be discussed below.

Mature TG 1 is variably myristoylated and palmitoylated, which causes this enzyme to associate with the plasma membrane [83]. The binding of this enzyme to membranes profoundly affects its substrate preference, especially with respect to which Q and $\mathrm{K}$ residues are modified. Moreover, when bound to membranes, TG 1 can catalyze the addition of ceramides to $\mathrm{Q}$ residues [8], which may contribute to the incorporation of fatty materials into tangles. The membrane-binding portion of TG 1 can be removed by proteolysis to generate a cytosolic form of the enzyme [83]. TG 2 and deacylated TG 1 share many of the same substrates $[84,85]$ and, therefore, cytosolic TG 1 may act on a number of the a forementioned TG 2 substrates (e.g., $\mathrm{AT}_{2}$ ).

\section{Increases in neuronal $\mathrm{Ca}^{2+}{ }_{i}$ in AD}

The extracellular milieu is sufficiently rich in $\mathrm{Ca}^{2+}(1-2 \mathrm{mM})$ to maximally stimulate proteolytically-activated factor XIII and any active TG 2 exported from cells [61-63], and to contribute to the stabilization of $A \beta$ plaques. Under these circumstances the major limits to activity are likely to be clearance via the cerebral circulation, incorporation into biological matrices (noncovalent associations and covalent attachment where one TG molecule acts as a substrate for another) and substrate availability. With respect to the last point, blood and interstitial fluid are poor sources of polyamines and, consequently, extracellular TG 2 would be expected to produce a greater number of $\gamma$-glutamyl- $\varepsilon$-lysine linkages than either bis- $\gamma$ glutamylpolyamine or $\gamma$-glutamylpolyamine linkages an expectation that has been substantiated by in vitro studies $[10,21]$.

Intracellular TGs may be activated by etiological factors associated with sporadic AD. Kuchibhotla et al. have demonstrated that the pathological deposition of A $\beta$-containing plaques 
resulted in a rise in $\mathrm{Ca}^{2+}{ }_{i}$ from approximately 80 to approximately $500 \mathrm{nM}$ in $20 \%$ of the neurons in the vicinity of the plaques [24]. Similarly, Busche et al. reported an increased frequency of spontaneous $\mathrm{Ca}^{2+}$ transients in approximately $20 \%$ of the neurons in neighboring plaques [86]. Thus, $A \beta$ plaques may facilitate the generation of tangles by TGs by elevating

$\mathrm{Ca}^{2+}{ }_{i}$ concentrations. How plaques allow $\mathrm{Ca}^{2+}$ into neurons has not been established. Busche et al. have argued that plaques may interfere with the glutamatergic inhibition of synaptic activity [86], whereas Kuchibhotla et al. suggest that these structures form $\mathrm{Ca}^{2+}$-conducting pores, modulate voltage-gated $\mathrm{Ca}^{2+}$ channels or generate an oxidative stress that releases calcium from intracellular stores [24]. The observations of these two groups were made using murine models of $\mathrm{AD}$ and the differences reported (i.e., increased $\mathrm{Ca}^{2+}{ }_{i}$ vs spontaneous $\mathrm{Ca}^{2+}$ transients) are most likely due to differences in methodologies and the genetic background of the mice. Regardless of their differences, these studies demonstrate that elevations in $\mathrm{Ca}^{2+}{ }_{i}$ concentrations are an important and consistent feature of sporadic AD etiology.

Some of the mutations that underlie familial AD also increase the concentration of $\mathrm{Ca}^{2+}{ }_{i}$ in the affected neurons. The ER is the major reservoir of $\mathrm{Ca}^{2+}$ within cells, and its $\mathrm{Ca}^{2+}$ stores are replenished by ATP-dependent $\mathrm{Ca}^{2+}$ pumps. However, passive $\mathrm{Ca}^{2+}$ efflux leak channels act in opposition to these pumps to ensure that the ER does not become overfilled with $\mathrm{Ca}^{2+}$. One consequence of overfilling the ER is an exaggerated efflux of $\mathrm{Ca}^{2+}$ in response to either $\mathrm{IP}_{3}$ or RyR activation. Presenilins 1 and 2 encode for passive $\mathrm{ER} \mathrm{Ca}^{2+}$ leak channels and mutations of these molecules account for approximately $40 \%$ of familial AD cases [87]. A significant number of these mutations ablate the leak activity of presenilins, causing both an overfilling of $\mathrm{Ca}^{2+}$ by the $\mathrm{ER}$ and an excessive $\mathrm{Ca}^{2+}$ efflux from this organelle upon stimulation $[88,89]$. Stutzmann and colleagues have demonstrated that mice bearing one of these presenilin 1 mutations (i.e., presenilin $1 \mathrm{M} 146 \mathrm{~V}$ ) show a threefold greater increase of $\mathrm{Ca}^{2+}{ }_{i}$ in response to $\mathrm{IP}_{3}$ relative to control animals [90]. Stutzmann and coworkers subsequently demon strated that this response was primarily due to the passage of $\mathrm{Ca}^{2+}$ through the RyR [91]. The number of RyRs increases with age and is associated with a greater rise in $\mathrm{IP}_{3}$-evoked $\mathrm{Ca}^{2+}{ }_{i}$ with age in presenilin 1 M146V-knockin mice [91]. Together, these observations suggest that increases in $\mathrm{Ca}^{2+}{ }_{i}$ levels, capable of inducing intracellular TG activity, are a consistent feature in AD.

\section{Increases in neuronal $\mathrm{Ca}^{2+}{ }_{i}$ during aging}

Aging is one of the major risk factors for $\mathrm{AD}$ and other neurodegenerative disorders. As in the case of animal AD models, the activation of RyRs is also thought to contribute to the elevations in $\mathrm{Ca}^{2+}{ }_{i}$, observed in the hippocampal neurons of aging rodents. These elevations are primarily caused by the opening of voltage-dependent $\mathrm{Ca}^{2+}$ channels and contribute to a number of electrophysiological phenomena, including the slowing of the after-hyperpolarization phase of action potentials with age, as well as increases in $\mathrm{Ca}^{2+}$ spikes, currents and transients [92]. Application of the RyR antagonist ryanodine to hippocampal slices lessens the effects of age on the after-hyperpolarization and synaptically activated $\mathrm{Ca}^{2+}$ transients. Based on this observation, Thibault et al. hypothesized that $\mathrm{Ca}^{2+}$ efflux from the ER, as mediated by the $\mathrm{RyR}$, is an important component of the age-dependent increase in neuronal $\mathrm{Ca}^{2+}{ }_{i}$ [92]. This hypothesis is further supported by studies that suggest the L-type voltage-dependent $\mathrm{Ca}^{2+}$ channels are situated close enough to RyRs to activate this ER channel [93].

It is important to note that the pathology of the aging rodent brain may be different from that of humans. Aging rodents do not normally succumb to either familial or sporadic AD. Indeed, the transfection of three separate mutated genes is required to produce a facsimile of human $\mathrm{AD}$ in mice replete with the behavioral manifestations [94]. Even so, fibroblasts isolated from $\mathrm{AD}$ patients do exhibit some of the aspects of altered $\mathrm{Ca}^{2+}$ homeostasis seen in $\mathrm{AD}$ mice [95]. However, the relevance of murine aging to $\mathrm{AD}$ remains to be established. It will also be important to determine the role of apoptosis in murine and human aging. Apoptosis commonly 
occurs in rodent models of neuro degeneration. Since apoptosis is usually restricted to dividing cells this is a remarkable observation (nondividing cells typically die by macroautophagy), and suggests that apoptosis is either unique to rodents or diseases such as $\mathrm{AD}$ per se. If the latter is true then strategies that limit apoptosis should have therapeutic benefit in human neurodegenerative diseases.

\section{HD: features \& TG hypothesis}

Huntington's disease is primarily a movement disorder resulting from the death of mediumsized spiny neurons in the striatum, and patients exhibit varying degrees of mental decline as the disease progresses. In addition to the affected sites, HD differs from most cases of AD in that the disease is due to mutations in a single gene. Despite its rarity - a frequency of $0.007 \%$ worldwide - the availability of pertinent animal models, and the notion that many fundamental processes underlying neurodegeneration are similar regardless of initiating factors or site of injury, has stimulated significant research interest into HD.

Huntingdon's disease is due to an expansion of CAG repeats in the huntingtin ( $h t t)$ gene and these mutations are inherited in an autosomal dominant manner. The CAG expansions encode stretches of polyglutamines (poly $\mathrm{Q}$ ) in the $\mathrm{N}$ terminus of the htt protein, and mutations giving rise to 39 or more contiguous $\mathrm{Q}$ residues in this protein invariably precipitate the disease [96]; the longer the repeat the earlier the onset of the disease and the greater its rate of progression $[97,98]$. DNA replication tends to expand mutant CAG repeat sequences, and consequently, the number of mutant poly $\mathrm{Q}$ residues in htt tends to increase with each succeeding generation, particularly in the case of paternal transmission. This phenomenon of 'anticipation' results in successively earlier disease onsets.

As in the case of $\mathrm{AD}$, polymeric aggregates are deposited in affected brain regions of $\mathrm{HD}$ patients [99]. The aggregates include mutant htt, which has a marked propensity to selfaggregate in vitro [100]. Green suggested that mutant htt might be an excellent substrate of TGs and that TG activity toward mutant htt might contribute to the etiology of HD [101]. TGs were hypothesized to promote the aggregation of mutant htt in a manner that correlated with the poly Q length. This hypothesis is supported by in vitro studies showing that contiguous $Q$ residues in model peptides/proteins [102-105] and mutant htt itself [106] are excellent TG substrates. Moreover, $\gamma$-glutamyl- $\varepsilon$-lysine linkages are present in htt-containing aggregates in intact HD brain [107].

\section{TG expression \& activity in HD}

The greater amount of protein-bound and free $\gamma$-glutamylamines in HD brains and CSF, as compared with controls, attests to the increased activation of cerebral TGs in this disease $[11-13,107]$. TG activity is also greater in postmortem samples of HD versus control brain $[104,108]$ and relates to elevations in the message and amounts of TG 2 proteins $[106,108]$. HD is accompanied by inflammation and mediators of this process, such as TNF- $\alpha$, may serve to increase the expression of TG 2 . The TG 2 promoter contains an NF- $\mathrm{kB}$ - binding region and TNF- $\alpha$ stimulates both the translocation and DNA binding of NF- $\mathrm{KB}$, as well as the expression of TG 2 in microglia and astrocytes [55,109]. As noted earlier, the activation of TG 2 (and possibly other TGs) may promote inflammation through the sustained activity of polyaminated phospholipase $\mathrm{A}_{2}$.

\section{Increases in neuronal $\mathrm{Ca}^{2+}{ }_{i}$ during $\mathrm{HD}$}

The activation of TGs may be an early and significant consequence of HD since mutant $h t t$ promotes $\mathrm{Ca}^{2+}{ }_{i}$ elevations capable of stimulating the activity of these enzymes. Wild-type $h t t$ binds to $\mathrm{IP}_{3}$ receptors and facilitates the release of $\mathrm{Ca}^{2+}$ through this combination channel- 
receptor [110]. However, mutant htt preferentially enhances the release of $\mathrm{Ca}^{2+}$ via the $\mathrm{IP}_{3}$ receptor following glutamate-dependent hydrolysis of $\mathrm{PIP}_{2}$ [111]. Glutamate excitoxicity in $\mathrm{HD}$ is thought to be promoted mainly via the NMDA receptor and the activity of this receptor is markedly increased in mutant htt-expressing mice [112,113]. Dopamine acts synergistically to increase glutamate-dependent $\mathrm{Ca}^{2+}{ }_{i}$, presumably through the protein kinase A-catalyzed phosphorylation of NMDA and AMPA receptors and through the dopamine type 2 receptormediated hydrolysis of $\mathrm{PIP}_{2}$ [114]. Together, these processes would be expected to significantly increase $\mathrm{Ca}^{2+}{ }_{i}$, and this has been confirmed in numerous studies with mice bearing disease-causing mutations in $h t t[115,116]$.

Mutant htt also appears to increase the sensitivity of the permeability transition pore to $\mathrm{Ca}^{2+}$, leading to dissipation of the mitochondrial membrane potential, and consequently, to a diminished capacity of this organelle to store $\mathrm{Ca}^{2+}[117-120]$. How mutant htt causes the above effects is not known, but may involve binding partners that attach to mutant poly $\mathrm{Q}$ sequences. These binding partners may also regulate TG activity.

\section{Polyglutamine-expanded htt, calmodulin \& TG in HD}

The $\mathrm{Ca}^{2+}$-binding protein calmodulin associates with poly Q-expanded htt and through this association regulates TG activity. Calmodulin was initially shown to regulate TG activity in platelets, chicken gizzard [121] and the human erythrocyte cytoskeleton [122]. It was subsequently demonstrated that inhibiting calmodulin or disrupting the association of calmodulin with poly Q-expanded htt with a peptide derived from calmodulin (amino acids 76 -127), reduces the ability of poly Q-expanded htt to act as a TG substrate [123-125]. In addition to preventing the TG from utilizing poly Q-expanded htt as a substrate, expression of this peptide reduced the cytotoxicity and $\mathrm{Ca}^{2+}{ }_{i}$ increase associated with expression of mutant htt $[124,125]$. These changes were selective, as neither total TG activity nor calmodulin-dependent kinase II activities were inhibited by the calmodulin peptide. In addition, the association of calmodulin with another calmodulin-dependent enzyme, calcineurin, was not disrupted by the calmodulin peptide [125]. Expression of the calmodulin peptide fragment in the striatum of a transgenic mouse model of HD lessened the weight loss and motor dysfunction typically seen in these animals [MUMA N, UNPUBLISHED DATA].

\section{Toxic mechanisms for TGs in HD}

Mice with HD (R6/1 transgenic mice expressing exon 1 of human $h t t$ that contains a greatly expanded polyglutamine domain [116 Q repeats]) with a TG $2^{-/-}$genotype live longer than littermates expressing $\mathrm{TG}^{+/+}$and the mutant htt fragment [126]. In the $\mathrm{R} 6 / 1: \mathrm{TG}^{-/-}$mice, the TG 2 knockout encompassed the whole body. Although one cannot rule out the possibility that the increased life expectancy in the R6/1: $\mathrm{TG}^{-1-}$ mice is due to some beneficial effect related to ablation of whole body TG2, it seems likely that the beneficial effect is due to local loss of brain TG 2. Thus, the percentage of abnormal brain cells in the various groups of mice at 18 and 25 weeks was found to be in the order R61>R6/1:TG $2^{+/-}>\mathrm{R} 6 / 1$ :TG $2^{-/-}$[126]. Moreover, the isopeptide levels in the detergent-insoluble fraction of brain at 25 weeks of age was also of the order R61>R6/1:TG $2^{+/-}>\mathrm{R} 6 / 1: \mathrm{TG}^{-/-}$[126]. These gradation effects argue for a local beneficial effect of TG 2 ablation. Interestingly, the number of intranuclear

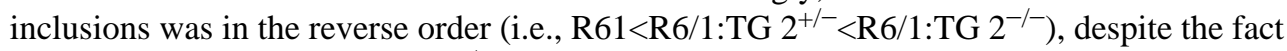
that the brains of the R6/1:TG $2^{-/-}$mice exhibited tenfold less $\gamma$-glutamyl- $\varepsilon$-lysine linkages than their R6/1 littermates [126]. Presumably, the residual $\gamma$-glutamyl- - -lysine bonds in the brains of $\mathrm{R} 6 / 1, \mathrm{TG}^{-/-}$mice are due to brain TGs other than TG 2 . The seemingly paradoxical finding of increased aggregates in the brains of the R6/1: $\mathrm{TG}^{-/-}$mice compared with those in brains of the R6/1 mice may be explained by the findings of Lai et al. alluded to above [14]. Thus, in the absence of TG 2, the poly Q domains will noncovalently form insoluble aggregates. In the presence of TG $2, \gamma$-glutamyl- $\varepsilon$-lysine crosslinking will retard the formation 
of these insoluble noncovalent aggregates. However, TG 2-catalyzed polyamination will a ntagonize this effect. At the present time it is not clear whether the soluble protein aggregates containing htt, the insoluble aggregates, or both, are toxic [14]. However, if the soluble form was more toxic this would explain the findings of Mastroberardino et al. [126] and might suggest that the level of polyamine in the brain is crucial to the contribution of TGs to HD. The levels of polyamines in the brain decrease with age [127]. Thus, the ability of the HD brain to prevent formation of soluble aggregates may be lessened with age. However, this possibility has not yet been investigated.

In addition to $\mathrm{HD}$, there are a number of other $\mathrm{CAG}$ /polyglutamine expansion diseases in which TGs are hypothesized to possibly contribute to the disease process. These diseases have been previously reviewed $[105,128,129]$.

\section{Parkinson disease}

Parkinson disease is the most common neurodegenerative disorder after AD. This disease results from the selective loss of dopaminergic neurons in the substantia nigra pars compacta $(\mathrm{SNc})$. In most cases, what causes the loss of these neurons is unknown. PD presents as tremor, bradykinesia, rigidity and postural instability. The affected brain regions contain intracytoplasmic aggregates known as Lewy bodies consisting of dense eosinophilic cores surrounded by pale halos [130]. These structures have also been identified in some cases of $\mathrm{AD}$ [131]. The major constituent of Lewy bodies is a 140-amino acid protein known as $\alpha$ synuclein [132]. A fragment of $\alpha$-synuclein (the nonamyloid component [NAC]) is also found in the Lewy bodies of PD patients [133] and in the neuritic plaques of AD patients [134]. Several lines of evidence suggest a central role of aggregated $\alpha$-synuclein in the etiology of PD. $\alpha$-Synuclein fibrils are neurotoxic when added to cultured cells [135,136], and the expression of human $\alpha$-synuclein in mice results in progressive accumulation of $\alpha$-synuclein inclusions and a concomitant loss of dopamine-containing neurons in the basal ganglia [137]. Finally, missense point mutations in $\alpha$-synuclein are associated with an early-onset, inherited form of PD $[138,139]$.

\section{TGs, $\mathrm{Ca}^{2+}$ \& Parkinson's disease}

As in the case of AD [59], greater amounts of TG 2 have been observed in the CSF of PD patients compared with control CSF [60]. $\alpha$-Synuclein spontaneously forms aggregates [140]. Interestingly, dopaminergic neurons of the PD SNc exhibit greater staining for TG 2 and $\gamma$ glutamyl- $\varepsilon$-lysine than those of aged-matched controls [141]. Immunoprecipitation studies using antibodies that recognize either $\alpha$-synuclein or $\gamma$-glutamyl-e-lysine have demonstrated the presence of $\gamma$-glutamyl- $\varepsilon$-lysine crosslinked mono- and oligomeric $\alpha$-synuclein in PD nigral neurons [141]. The formation of intramolecular $\gamma$-glutamyl- $\varepsilon$-lysine crosslinks in $\alpha$-synuclein results in a monomeric and more compact form of this protein that is unable to polymerize into $\alpha$-synuclein fibrils $[80,81]$. Based on these observations, it has been suggested that TGs in neurodegenerative diseases act, to some extent, to curb the formation of insoluble, toxic oligomers of $\alpha$-synuclein, htt and other disease-relevant proteins. Notwithstanding the appeal of this idea, it has yet to be demonstrated that soluble $\alpha$-synuclein monomers or htt oligomers are innocuous. Indeed, the amount of intramolecularly crosslinked $\alpha$-synuclein in nigral dopaminergic neurons was found to correlate with the progression of PD [141]. $\gamma$-Glutamyl$\varepsilon$-lysine-mediated crosslinking has the potential to modify the ubiquitination of proteins since ubiquitin is bound to lysine residue by a reaction remarkably similar to TG-catalyzed transamidation. Thus, $\gamma$-glutamyl-e-lysine crosslinked proteins may be inappropriately ubiquitinated and congest proteasomes. Components of the ubiquitin proteasome system have been identified in aggregates in two polyglutamine expansion diseases [142-144]. In toto, these observations suggest that the TG substrate pools in the brain change during aging or as neuro 
degenerative diseases progress, and that these changes may lead to the production of neurotoxic species. These changes range from decrements in substrate pools, as in the case of polyamines in the aging brain [127], to post-translational modifications of the substrates including proteolysis [65], and phosphorylation of $\alpha$-synuclein [136]. TGs may also contribute to formation of toxic aggregates by polymerizing with molecules, such $\alpha$-synuclein and poly Qexpanded htt, and TG 2 has been identified within the deposits of these proteins [107].

Unlike other excitable cells in the brain, SNc neurons fire autonomously at a frequency of 2 $-4 \mathrm{~Hz}$, very much like cardiac pacemaker cells [145], although in PD the neurons exhibit bursts of cyclic firing rather than a continuous train of action potentials [146]. Similar to heart cells, SNc neurons also use $\mathrm{Ca}^{2+}$ rather than $\mathrm{Na}^{+}$to carry the current. $\mathrm{Ca}^{2+}$ enters $\mathrm{SNc}$ cells by way of L-type currents, which open frequently to accommodate the pacemaker functions of these cells. Glutamate-evoked opening of L-type channels causes $\mathrm{Ca}^{2+}{ }_{i}$ peak increases of $100 \mu \mathrm{M}$ [147], which is more than enough to stimulate TG activity. Surmeier has suggested that the mitochondria in diseased SNc neurons leak $\mathrm{Ca}^{2+}$ into the cytosol since these organelles are often damaged in PD [145]. This suggestion is supported by the observation that the expression of calbindin, which binds $\mathrm{Ca}^{2+}$, confers protection against mitochondrial toxins in cultured pheochromacytoma 12 (PC12) cells [148]. Thus, under physiological and pathological conditions, TGs are either continuously activated in SNc neurons or regulated in a different manner than in other cells. The latter possibility is most likely; however, at present, little is known regarding the regulation of $\mathrm{TG}$ in either $\mathrm{SNc}$ or $\mathrm{PD}$.

\section{Progressive supranuclear palsy}

Progressive supranuclear palsy (PSP) is a parkinsonian-like movement disorder characterized clinically by early postural instability, supranuclear vertical gaze palsy, and behavioral and cognitive disturbances [149]. This disease is characterized by neuronal loss, gliosis, neurofibrillary tangles, neuropil thread and tau immuno-reactive astrocytes.

Immunoprecipitated proteins containing $\gamma$-glutamyl- $\varepsilon$-lysine crosslinks from the affected brain regions in PSP exhibit labeling for paired helical filaments tau, indicative of the actions of TG in this disease [150]. Increased TG activity and increased expression of TG 1 and 2 at the protein and mRNA level has also been demonstrated for the selectively vulnerable brain regions in PSP [151]. $\mathrm{Ca}^{2+}$ homeostasis is thought to be perturbed during PSP and may act to activate TGs in this disease [152].

\section{Depression \& TGs}

Depression is a common symptom of HD and other neurodegenerative diseases such as AD. Signaling via the serotonergic pathway is an important component of depression, and depression is often successfully treated with drugs that act to modulate this signaling. TGs appear to influence serotonergic signaling by binding serotonin to the Rac1 G protein as indicated by coimmunoprecipitation of Rac 1 and serotonin $[153,154]$. Moreover, this binding is blocked with two strategies that attenuate TG activity, namely, treatment of cells with either small interfering RNA against TG 2 or cystamine. The identity of the TG-catalyzed bond(s) between serotonin and Rac 1 has as yet not been determined and the significance of its formation in neurodegenerative diseases awaits further research.

\section{TG inhibitors}

A major emphasis in this review has been the role of $\mathrm{Ca}^{2+}$ in activating TGs in neurodegenerative diseases. Intracellular $\mathrm{Ca}^{2+}$ concentrations are increased in $\mathrm{AD}$ and $\mathrm{HD}$, as is TG activity. However, the mechanisms by which $\mathrm{Ca}^{2+}$ increases in these diseases varies considerably and argues against the use of calcium-channel blockers as possible therapeutics. By contrast, the activation of TGs in these diseases is a common and potentially damaging 
consequence of the rise in $\mathrm{Ca}^{2+}{ }_{i}$. Thus, $\mathrm{TG}$ inhibitors are theoretically good candidates as therapeutics in neurodegenerative disorders.

Numerous small amine-bearing compounds, including polyamines, cysteamine, cystamine, hydroxylamine, methylamine and histamine act as competitive inhibitors of transamidation catalyzed by TGs $[5,155,156]$. A primary amine bound to an aliphatic unbranched carbon chain of 4 or 5 saturated carbon atoms is a common characteristic of this class of inhibitors, although shorter amines, such as hydroxylamine, methylamine and cysteamine are also active, as is cystamine. These compounds act as alternative TG substrates, and thereby divert the activity of TGs. Of this group of compounds, cystamine $\left(\mathrm{H}_{2} \mathrm{NCH}_{2} \mathrm{CH}_{2} \mathrm{SSCH}_{2} \mathrm{CH}_{2} \mathrm{SH}\right.$; which also has the possibility of reacting directly with the cysteine at the active site by sulfide-disulfide interchange) has been the most extensively studied as a potential therapeutic and has been shown to be beneficial in animal models of $\mathrm{HD}[13,157,158]$ and a neurotoxin model of PD [159]. However, cystamine elicits several changes that may contribute to neuronal survival, making it difficult to assess the role of TG inhibition in cystamine-induced neuroprotection. For example, administration of cystamine to mice raises the level of brain cysteine $[160,161]$. Both cystamine and cysteamine raise the level of brain-derived neurotropic factor [162] in animal models of HD. The compounds also inhibit macroautophagy [163] and apoptosis [164] in cell models. The inhibition of apoptosis in HD cell models by cystamine is thought to be caused by inhibition of caspase 3 activity [164]. Moreover, cystamine extends the lifespan to a similar extent in a mouse model of $\mathrm{HD}$ in which TG 2 is ablated (R6/2:TG2 ${ }^{-/-}$mice) to that observed in control mice (R6/2:TG2 ${ }^{+/+}$littermates), indicating that the compound may not be directly working through inhibition of TG2 [165]. However, chronic administration of cystamine to mice results in decreased total TG activity in the brain [13,157]. This decrease may be due to an inhibition of the transcription of TGs by cystamine-derived cysteamine. In support of this idea, cysteamine attenuates the DNA binding of two factors - activator protein 1 and NF-אB [166] - that bind to the TG 1 and TG 2 promoters $[53,56,167]$.

Many TG inhibitors have been designed or discovered by screening of compound libraries. Irreversible TG inhibitors include sulfonamides [168], iodoacetamide [169], alkyl isocyanates [170], phenylthioureas [171,172], 3-halo-4,5-dihydroisoxazoles [173-175], tyrosinamidomethyl dihydrohaloisoxazoles [176], sulfonium methyl ketones [177], 2-[(2oxoproyl)thio]imidazolium derivatives [178], and $\alpha \beta$-unsaturated amides, epoxides and 1,2,4,thiadiazoles built around the well known acyl substrate Cbz-L-Gln-Gly of guinea pig TG 2 [179-181]. Many compounds in this last category are irreversible inhibitors in the micromolar or submicromolar range.

Comparison of the structures and activities of these compounds revealed the importance of the length and the electronic nature of the side chains of the inhibitor analogues of Cbz-Gln-Gly [180]. Keillor et al. suggest that X-ray crystallographic analysis of TG 2, with or without the inhibitor bound at the active site, might prove useful in the design of a more potent second generation of thiadiazole TG 2 inhibitors [179-181]. Recently, Stein and colleagues used a high-throughput procedure to screen a library of 110,000 drug-like molecules to search for inhibitors of TG $2[182,183]$. The acyl donor and acyl acceptor substrates used were $N, N$ dimethylcasein and $\mathrm{N}$-boc-lys-NH- $\mathrm{CH}_{2}-\mathrm{CH}_{2}-\mathrm{NH}$-dansyl, respectively. The screen produced 104 candidates including competitive, mixed-site and GTP-binding site inhibitors [182,183]. Particularly effective inhibitors were thieno[2,3-d]pyrimidin-4-one acylhydrazide and derivatives [184]. Lai et al. have also used a high-throughput screening procedure to screen for inhibitors of human TG 2 [185]. The authors identified several inhibitors, the most potent of which were ZM39923, a Janus kinase inhibitor, and its metabolite ZM49829, with IC $_{50}$ values of $10 \mathrm{nM}$ and $5 \mathrm{nM}$, respectively. Tyrphostin and vitamin $\mathrm{K} 3$ were found to have $\mathrm{IC}_{50}$ values in the micromolar range. The agents appeared to act in part by interfering with the reduction of the vicinal disulfide needed for activation of TG. Interestingly, several of the 
agents uncovered by the screening were able to improve survival times in a Drosophila melanogaster model of a polyglutamine expansion disease (Machado-Joseph disease) [185].

A number of groups have investigated the potential of peptide-based TG inhibitors. These peptides are typically derived from TG substrates or binding partners and consequently, have the potential to very precisely modulate the activity of these enzymes. For example, Kim and colleagues, noting that uteroglobin and lipocortin-1 contain common sequences that antagonize the interaction of TG 2 and phospholipase $A_{2}$, synthesized variants of these sequences that prevented both the polyamination of phospholipase $\mathrm{A}_{2}$ and experimentally induced allergic conjunctivitis [186]. Similarly, a calmodulin-derived peptide that blocks the interaction of calmodulin with expanded poly Q attenuated the action of TG on mutant htt $[124,125]$ and had therapeutic benefit in a transgenic murine HD model [Muma netaL, UNPUBLISHEd Data].

While the aforementioned peptides presumably act in a competitive manner to inhibit TG activity, other peptides that act irreversibly have been generated using diazo-oxonorleucine (DON) in place of Q residues. The diazo moiety of DON reacts irreversibly with the TG 2 active site catalytic cysteine residue. Khosla and coworkers synthesized Ac-P(DON)LPF$\mathrm{NH}_{2}$, based on a common sequence in gluten proteins (PQLPY) that is acted upon by TG 2, and employed it to investigate the conformation states of TG 2 [32]. This pentapeptide inhibits TG 2 with a $\mathrm{K}_{\mathrm{i}}$ of $60 \mathrm{nM}$ and $\mathrm{k}_{1}$ of $0.5 \mathrm{~min}^{-1}$, but as of yet, has not been tested in models of neurodegeneration. The diazo grouping is moderately reactive and the possibility existed that DON-containing peptides might be cytotoxic. However, Ratan and coworkers have shown that a DON-containing peptide [Z-DON-Gln-Ile-Val-OMe] is especially useful in studying the biological effects of TG inhibition in normal and HD cells in culture and in a Drosophila melanogaster model of HD. Thus far, the results have only been presented at national meetings $[187,188]$; however, a more comprehensive report has been submitted for publication. The findings may be summarized as follows: TG 2 appears to be a transcriptional regulator, not only of selected metabolic genes (cytochrome $c$ and $P g c l a$ ), but also of a large number of genes that are dysregulated in neural cells expressing a mutant form of htt. Inhibition of TG 2 restores downregulated metabolic genes (cytochrome $c$ and Pgcla) in mutant htt-expressing cells, and derepression of this pathway increases downstream indicators of metabolic function, increases survival in a cellular model of HD and decreases the incidence of defective ommatidia in a fly model of HD [188]. Dysregulation of metabolism in HD is well documented. For example, Gines et al. demonstrated a deficit in cAMP in HD-knockin mice and in striatal cell models of HD [189]. The findings suggested that the reduction of cAMP leads to a mitochondrial energy deficit [189]. Whether TGs cause a change in cAMP-responsive element-mediated gene transcription of proteins generally involved in metabolic regulation in HD remains to be determined.

While the work from Ratan's group is preliminary, it does strongly implicate a role for TGs in the progression of HD. The next stage is to determine other possible promoters with which TG 2 may interact and identify transcriptional proteins that are possibly covalently modified by TGs. If Z-DON-Gln-Ile-Val-OMe (or analogues) is to prove useful in rodent models of neurodegenerative diseases, further work is needed to determine whether the compound passes the BBB and inhibits endogenous brain TGs.

Yuan et al. have demonsrated that small molecule TG 2 inhibitors, such as the reversible inhibitor monodansylcadaverine and the irreversible dihydroisoxazole inhibitors, KCA075 or KCC009, promote apoptosis in glioma cells and sensitize the tumors to the chemotherapeutic agent N,N'-bis(2-chloroethyl)-N-nitrosourea [190,191]. It was suggested that TG2 is a potential target to enhance cell death and chemosensitivity in glioblastomas $[190,191]$. The TG inhibitors developed by Yuan et al. $[190,191]$ might also be useful for investigating the role of TGs in neurodegenerative diseases. 


\section{Executive summary}

Elevation of intracellular $\mathrm{Ca}^{2+}\left(\mathrm{Ca}^{2+}{ }_{i}\right)$ is a consistent feature of Alzheimer's disease and Huntington's disease.

- One important consequence of this increase of $\mathrm{Ca}^{2+}{ }_{i}$ is likely to be the activation of transglutaminases (TGs), which, increasing evidence suggests, contributes to neurodegenerative processes.

- The mechanisms by which TG-modified products induce cytotoxicity in neural tissues have not been clearly identified, but studies investigating the toxicity of soluble and insoluble TG-generated crosslinked aggregates suggest some very interesting possibilities.

- One intriguing possibility is that changes in the ratio of $\gamma$-glutamylpolyamine/bis- $\gamma$ glutamylpolyamine to $\gamma$-glutamyl- $\varepsilon$-lysine linkages may determine the solubility, and by extension, the toxicity of TG-catalyzed aggregates. Other possibilities include alteration of transcription factor machinery.

- Recent studies with rationally designed TG inhibitors and with inhibitors uncovered by high-throughput screening show that these compounds have beneficial effects in animal/cellular models of polyglutamine-expansion neurodegenerative diseases. TG inhibitors have also been shown to be effective in mice harboring glioblastomas.

- It is predicted that this promising start with TG inhibitors will be extended to animal models of more common neurodegenerative diseases and will eventually lead to clinical trials in humans with devastating neurological diseases.

\section{Acknowledgments}

Part of the work described herein from the authors' laboratories was funded in part by NIH grant 2P01 AG14930 (to Arthur JL Cooper), R01MH068612 (to Nancy A Muma) and a grant from the High Q Foundation (to Nancy A Muma). Part of the work described herein was conducted when Thomas M Jeitner and Arthur JL Cooper were at the Burke Medical Research Institute, White Plains, and when Nancy A Muma was at Loyola University Chicago. The authors have no other relevant affiliations or financial involvement with any organization or entity with a financial interest in or financial conflict with the subject matter or materials discussed in the manuscript apart from those disclosed.

No writing assistance was utilized in the production of this manuscript.

\section{Bibliography}

Papers of special note have been highlighted as:

- of interest

m of considerable interest

1m. Kim SY, Grant P, Lee JH, et al. Differential expression of multiple transglutaminases in human brain. Increased expression and cross-linking by transglutaminases 1 and 2 in Alzheimer's disease. J. Biol. Chem 1999;274:30715-33021. [PubMed: 10521460] [a of considerable interestFirst study to demonstrate that at least three transglutaminases (TGs) are present in human brain and that Alzheimer's disease (AD) brain has greatly increased levels of protein crosslinks.]

2. Citron BA, SantaCruz KS, Davies PJA, et al. Intron-exon swapping of transglutaminase mRNA and neuronal Tau aggregation in Alzheimer's disease. J. Biol. Chem 2001;276:3295-3301. [PubMed: 11013236]

3a. Wilhelmus MM, Grunberg SC, Bol JG, et al. Transglutaminases and transglutaminase-catalyzed cross-links colocalize with the pathological lesions in Alzheimer's disease brain. Brain Pathol. 2008 
DOI: 10.1111/j.1750-3639.2008.00197.x. (Epub ahead of print). [ $\mathbf{\square}$ of interestImportant demonstration of TGs and pathological lesions in AD brain.]

4๘. Hadjivassiliou M, Aeschlimann P, Strigun A, et al. Autoantibodies in gluten ataxia recognize a novel neuronal transglutaminase. Ann. Neurol 2008;64:332-343. [PubMed: 18825674] [匹 of interestDemonstration of TG 6 in human brain.]

5. Lorand L, Graham RM. Transglutaminases: crosslinking enzymes with pleiotropic functions. Nat. Rev. Mol. Cell Biol 2003;4:140-156. [PubMed: 12563291]

6. Molberg Ø, MacAdam SN, Korner R, et al. Tissue transglutaminase selectively modifies gliadin peptides that are recognized by gut-derived T cells in celiac disease. Nat. Med 1998;4:713-717. [PubMed: 9623982]

7. Van de Wal Y, Kooy Y, van Veelen P, et al. Selective deamidation by tissue transglutaminase strongly enhances gliadin-specific T cell reactivity. J. Immunol 1998;161:1585-1588. [PubMed: 9712018]

8. Nemes Z, Marekov LN, Fésüs L, et al. A novel function for transglutaminase 1: attachment of longchain $\Omega$-hydroxyceramides to involucrin by ester bond formation. Proc. Natl Acad. Sci. USA 1999;96:8402-8407. [PubMed: 10411887]

9. Folk JE, Park MH, Chung SI, et al. Polyamines as physiological substrates for transglutaminases. J. Biol. Chem 1980;255:3695-3700. [PubMed: 6102569]

10. Piacentini M, Martinet N, Beninati S, et al. Free and protein-conjugated polyamines in mouse epidermal cells. Effect of high calcium and retinoic acid. J. Biol. Chem 1988;263:3790-3794. [PubMed: 3346223]

11. Jeitner TM, Matson WR, Folk JE, et al. Increased levels of $\gamma$-glutamylamines in Huntington disease CSF. J. Neurochem 2008;106:37-44. [PubMed: 18422943] [ $\mathbf{m}$ of interestFirst demonstration of increased $\gamma$-glutamylpolyamines in Huntington's disease (HD) brain.]

12. Jeitner TM, Bogdanov MB, Matson WR, et al. $\mathrm{N}^{\varepsilon}$-( $\gamma$-l-glutamyl)-l-lysine (GGEL) is increased in cerebrospinal fluid of patients with Huntington's disease. J. Neurochem 2001;79:1109-1112. [PubMed: 11739625]

13. Dedeoglu A, Kubilus JK, Jeitner TM, et al. Therapeutic effects of cystamine in a murine model of Huntington's disease. J. Neurosci 2002;22:8942-8950. [PubMed: 12388601]

14. Lai TS, Tucker T, Burke JR, et al. Effect of tissue transglutaminase on the solubility of proteins containing expanded polyglutamine repeats. J. Neurochem 2004;88:1253-1260. [PubMed: 15009681]

15. Konno T, Morii T, Shimizu H, et al. Paradoxical inhibition of protein aggregation and precipitation by transglutaminase-catalyzed intermolecular cross-linking. J. Biol. Chem 2005;280:17520-17525. [PubMed: 15731111]

16. Fink ML, Folk JE. $\gamma$-Glutamylamine cyclotransferase. An enzyme involved in the catabolism of $\varepsilon$ ( $\gamma$-glutamyl)lysine and other $\gamma$-glutamylamines. Mol. Cell. Biochem 1981;38:59-67. [PubMed: 6117008]

17. Cordella-Miele E, Miele L, Beninati S, et al. Transglutaminase-catalyzed incorporation of polyamines into phospholipase A2. J. Biochem 1993;113:164-173. [PubMed: 8096844]

18. Masuda M, Betancourt L, Matsuzawa T, et al. Activation of rho through a cross-link with polyamines catalyzed by Bordetella dermonecrotizing toxin. EMBO J 2000;19:521-530. [PubMed: 10675321]

19. Masuda M, Minami M, Shime H, et al. In vivo modifications of small GTPase Rac and Cdc42 by Bordetella dermonecrotic toxin. Infect. Immun 2002;70:998-1001. [PubMed: 11796639]

20匹. Folk JE, Mullooly JP, Cole PW. Mechanism of action of guinea pig liver transglutaminase. II. The role of metal in enzyme activation. J. Biol. Chem 1967;242:1838-1844. [PubMed: 6024774] [ロ of interestPaper of historical interest.]

21. Martinet N, Beninati S, Nigra TP, et al. N1N8-Bis( $\gamma$-glutamyl)spermidine cross-linking in epidermalcell envelopes. Comparison of cross-link levels in normal and psoriatic cell envelopes. Biochem. J 1990;271:305-308. [PubMed: 2241917]

22. Murthy SN, Wilson J, Guy SL, et al. Intramolecular crosslinking of monomeric fibrinogen by tissue transglutaminase. Proc. Natl Acad. Sci. USA 1991;88:10601-10604. [PubMed: 1683705]

23. Wilson J, Rickles FR, Armstrong PB, et al. $\mathrm{N}^{\varepsilon}(\gamma$-glutamyl)lysine crosslinks in the blood clot of the horseshoe crab, Limulus polyphemus. Biochem. Biophys. Res. Commun 1992;188:655-661. [PubMed: 1445311] 
24. Kuchibhotla KV, Goldman ST, Lattarulo CR, et al. A $\beta$ plaques lead to aberrant regulation of calcium homeostasis in vivo resulting in structural and functional disruption of neuronal networks. Neuron 2008;59:214-225. [PubMed: 18667150]

25. Zhang J, Lesort M, Guttmann RP, et al. Modulation of the in situ activity of tissue transglutaminase by calcium and GTP. J. Biol. Chem 1998;273:2288-2295. [PubMed: 9442073]

26. Tucholski J, Kuret J, Johnson GVW. Tau is modified by tissue transglutaminase in situ: possible functional and metabolic effects of polyamination. J. Neurochem 1999;73:1871-1880. [PubMed: 10537045]

27. Casadio R, Polverini E, Mariani P, et al. The structural basis for the regulation of tissue transglutaminase by calcium ions. Eur. J. Biochem 1999;262:672-679. [PubMed: 10411627]

28m. Ahvazi B, Kim HC, Kee SH, et al. Three-dimensional structure of the human transglutaminase 3 enzyme: binding of calcium ions changes structure for activation. EMBO J 2002;21:2055-2067. [PubMed: 11980702] [ $\mathbf{\square}$ of interestImportant X-ray crystallographic study of a TG.]

29. Liu S, Cerione RA, Clardy J. Structural basis for the guanine nucleotide-binding activity of tissue transglutaminase and its regulation of transamidation activity. Proc. Natl Acad. Sci. USA 2002;99:2743-2747. [PubMed: 11867708]

30. Ahvazi B, Boeshans KM, Idler W, et al. Roles of calcium ions in the activation and activity of the transglutaminase 3 enzyme. J. Biol. Chem 2003;278:23834-23841. [PubMed: 12679341]

31. Boeshans KM, Mueser TC, Ahvazi B. A three-dimensional model of the human transglutaminase 1: insights into the understanding of lamellar ichthyosis. J. Mol. Model 2007;13:233-246. [PubMed: 17024410]

32.. Pinkas DM, Strop P, Brunger AT, et al. Transglutaminase 2 undergoes a large conformational change upon activation. PLoS Biol 2007;5:E327. [PubMed: 18092889] [ of interestDemonstrates the major changes in TG 2 topology during the catalytic cycle.]

33. Andreotti AH. Native state proline isomerization: an intrinsic molecular switch. Biochemistry 2003;42:9515-9524. [PubMed: 12911293]

34. Andreotti AH. Opening the pore hinges on proline. Nat. Chem. Biol 2006;2:13-14. [PubMed: 16408084]

35. Sarkar P, Reichman C, Saleh T, et al. Proline cis-trans isomerization controls autoinhibition of a signaling protein. Mol. Cell 2007;25:413-426. [PubMed: 17289588]

36. Chazin WJ, Kördel J, Drakenberg T, et al. Proline isomerism leads to multiple folded conformations of calbindin D9k: direct evidence from two-dimensional ${ }^{1} \mathrm{H}$ NMR spectroscopy. Proc. Natl Acad. Sci. USA 1989;86:2195-2198. [PubMed: 2928325]

37. Datta S, Antonyak MA, Cerione RA. Importance of $\mathrm{Ca}^{2+}$-dependent transamidation activity in the protection afforded by tissue transglutaminase against doxorubicin-induced apoptosis. Biochemistry 2006;45:13163-13174. [PubMed: 17073438]

38. Sugimura Y, Hosono M, Wada F, et al. Screening for the preferred substrate sequence of transglutaminase using a phage-displayed peptide library: identification of peptide substrates for TGASE 2 and factor XIIIA. J. Biol. Chem 2006;281:17699-17706. [PubMed: 16636049]

39. Iismaa SE, Holman S, Wouters MA, et al. Evolutionary specialization of a tryptophan indole group for transition-state stabilization by eukaryotic transglutaminases. Proc. Natl Acad. Sci. USA 2003;100:12636-12641. [PubMed: 14566064] [ of interestImportant study of TG mechanism.]

40. Eigel WN, Randolph HE. Preparation of whole $\gamma$-casein by treatment with calcium phosphate gel. J. Dairy. Sci 1974;57:1444-1447. [PubMed: 4443459]

41. Bungay PJ, Owen RA, Coutts IC, et al. A role for transglutaminase in glucose-stimulated insulin release from the pancreatic $\beta$-cell. Biochem. J 1986;235:269-278. [PubMed: 2874792]

42. Tiraboschi P, Hansen LA, Thal LJ, et al. The importance of neuritic plaques and tangles to the development and evolution of AD. Neurology 2004;62:1984-1989. [PubMed: 15184601]

43. Mattson MP. Pathways towards and away from Alzheimer's disease. Nature 2004;430:631-639. [PubMed: 15295589]

44. Hardy J, Allsop D. Amyloid deposition as the central event in the aetiology of Alzheimer's disease. Trends Pharmacol. Sci 1991;12:383-388. [PubMed: 1763432]

45. Nistor M, Don M, Parekh M, et al. $\alpha$ - and $\beta$-secretase activity as a function of age and $\beta$-amyloid in Down syndrome and normal brain. Neurobiol. Aging 2007;28:1493-1506. [PubMed: 16904243] 
46. Holmes C, Boche D, Wilkinson D, et al. Long-term effects of A $\beta 42$ immunisation in Alzheimer's disease: follow-up of a randomised, placebo-controlled Phase I trial. Lancet 2008;372:216-223. [PubMed: 18640458]

47. Schmitz C, Rutten BP, Pielen A, et al. Hippocampal neuron loss exceeds amyloid plaque load in a transgenic mouse model of Alzheimer's disease. Am. J. Pathol 2004;164:1495-1502. [PubMed: 15039236]

48. Mudher A, Lovestone S. Alzheimer's disease - do tauists and baptists finally shake hands? Trends Neurosci 2002;25:22-26. [PubMed: 11801334]

49. Johnson GVW, Cox TM, Lockhart JP, et al. Transglutaminase activity is increased in Alzheimer's disease brain. Brain Res 1997;751:323-329. [PubMed: 9099822]

50. Singer SM, Norlund MA, Lee JM, et al. Transglutaminase cross-links in neurofibrillary tangles and paired helical filament tau early in Alzheimer's disease. Neurochem. Int 2002;40:17-30. [PubMed: 11738469]

51. Phillips MA, Jessen BA, Lu Y, et al. A distal region of the human TGM1 promoter is required for expression in transgenic mice and cultured keratinocytes. BMC Dermatol 2004;4:2. [PubMed: 15061870]

52. Ritter SJ, Davies PJ. Identification of a transforming growth factor- $\beta 1 /$ bone morphogenetic protein 4 (TGF- $\beta 1 / B M P 4)$ response element within the mouse tissue transglutaminase gene promoter. J. Biol. Chem 1998;273:12798-12806. [PubMed: 9582307]

53. Kuncio GS, Tsyganskaya M, Zhu J, et al. TNF- $\alpha$ modulates expression of the tissue transglutaminase gene in liver cells. Am. J. Physiol 1998;274:G240-G245. [PubMed: 9486175]

54. Park KC, Chung KC, Kim YS, et al. Transglutaminase 2 induces nitric oxide synthesis in BV-2 microglia. Biochem. Biophys. Res. Commun 2004;323:1055-1062. [PubMed: 15381106]

55. Campisi A, Caccamo D, Li Volti G, et al. Glutamate-evoked redox state alterations are involved in tissue transglutaminase upregulation in primary astrocyte cultures. FEBS. Lett 2004;578:80-84. [PubMed: 15581620]

56. Kim Y, Park YW, Lee YS, et al. Hyaluronic acid induces transglutaminase II to enhance cell motility; role of Rac1 and FAK in the induction of transglutaminase II. Biotechnol. Lett 2008;30:31-39. [PubMed: 17680210]

57 . Festoff BW, SantaCruz K, Arnold PM, et al. Injury-induced 'switch' from GTP-regulated to novel GTP-independent isoform of tissue transglutaminase in the rat spinal cord. J. Neurochem 2002;81:708-718. [PubMed: 12065630] [ of interestA novel truncated form of TG 2.]

58. Antonyak MA, Jansen JM, Miller AM, et al. Two isoforms of tissue transglutaminase mediate opposing cellular fates. Proc. Natl Acad. Sci. USA 2006;103:18609-18614. [PubMed: 17116873]

59. Bonelli RM, Aschoff A, Niederwieser G, et al. Cerebrospinal fluid tissue transglutaminase as a biochemical marker for Alzheimer's disease. Neurobiol. Dis 2002;11:106-110. [PubMed: 12460550]

60. Vermes I, Steur EN, Jirikowski GF, et al. Elevated concentration of cerebrospinal fluid tissue transglutaminase in Parkinson's disease indicating apoptosis. Mov. Disord 2004;19:1252-1254. [PubMed: 15368613]

61. Aeschlimann D, Mosher D, Paulsson M. Tissue transglutaminase and factor XIII in cartilage and bone remodeling. Semin. Thromb. Hemost 1996;22:437-443. [PubMed: 8989828] [匹 of interestGood review of some of the physiological roles of TG2 and factor XIII.]

62. Zemskov EA, Janiak A, Hang J, et al. The role of tissue transglutaminase in cell-matrix interactions. Front. Biosci 2006;11:1057-1176. [PubMed: 16146797]

63. El Nahas AM, Abo-Zenah H, Skill NJ, et al. Elevated $\varepsilon$-( $\gamma$-glutamyl)lysine in human diabetic nephropathy results from increased expression and cellular release of tissue transglutaminase. Nephron Clin. Pract 2004;97:C108-C117. [PubMed: 15292688]

64. Siegel M, Strnad P, Watts RE, et al. Extracellular transglutaminase 2 is catalytically inactive, but is transiently activated upon tissue injury. PLoS ONE 2008;3:E1861. [PubMed: 18365016]

65. Jensen PH, Sørensen ES, Petersen TE, et al. Residues in the synuclein consensus motif of the $\alpha$ synuclein fragment, NAC, participate in transglutaminase-catalysed cross-linking to Alzheimerdisease amyloid $\beta A 4$ peptide. Biochem. J 1995;310:91-94. [PubMed: 7646476]

66. Dudek SM, Johnson GVW. Transglutaminase facilitates the formation of polymers of the $\beta$-amyloid peptide. Brain Res 1994;651:129-133. [PubMed: 7922559] 
67. Hartley DM, Zhao C, Speier AC, et al. Transglutaminase induces protofibril-like $\beta$-protein assemblies that are protease-resistant and inhibit long-term potentiation. J. Biol. Chem 2008;283:16790-16800. [PubMed: 18397883]

68. Abdalla S, Lother H, El Missiry A, et al. Angiotensin II AT2 receptor oligomers mediate G-protein dysfunction in an animal model of Alzheimer disease. J. Biol. Chem 2009;284:6554-6565. [PubMed: 19074441]

69. Abdalla S, Lother H, El Missiry A, et al. Dominant negative AT2 receptor oligomers induce G-protein arrest and symptoms of neurodegeneration. J. Biol. Chem 2009;284:6566-6574. [PubMed: 19074439]

70. Cooper AJL, Sheu KR, Burke JR, et al. Transglutaminase-catalyzed inactivation of glyceraldehyde 3-phosphate dehydrogenase and $\alpha$-ketoglutarate dehydrogenase complex by polyglutamine domains of pathological length. Proc. Natl Acad. Sci. USA 1997;94:12604-12609. [PubMed: 9356496]

71. Gentile V, Sepe C, Calvani M, et al. Tissue transglutaminase-catalyzed formation of high-molecularweight aggregates in vitro is favored with long polyglutamine domains: a possible mechanism contributing to CAG-triplet diseases. Arch. Biochem. Biophys 1998;352:314-321. [PubMed: 9587422]

72. Cooper AJL, Wang J, Pasternack R, et al. Lysine-rich histone (H1) is a lysyl substrate of tissue transglutaminase: possible involvement of transglutaminase in the formation of nuclear aggregates in (CAG)n/Qn expansion diseases. Dev. Neurosci 2000;22:404-417. [PubMed: 11111157]

73. Nemes Z, Devreese B, Steinert PM, et al. Cross-linking of ubiquitin, HSP27, parkin, and $\alpha$-synuclein by $\gamma$-glutamyl- $\varepsilon$-lysine bonds in Alzheimer's neurofibrillary tangles. FASEB J 2004;18:1135-1137. [PubMed: 15132984] [ of interestIdentification of major crosslinked proteins in AD brain.]

74. Norlund MA, Zainelli G, Lee J, et al. Elevated transglutaminase-induced bonds in Alzheimers PHF tau. Brain Res 1999;851:154-163. [PubMed: 10642839]

75. Appelt DM, Balin BJ. The association of tissue transglutaminase with human recombinant tau results in the formation of insoluble filamentous structures. Brain Res 1997;745:21-31. [PubMed: 9037390]

76. Dudek SM, Johnson GVW. Transglutaminase catalyzes the formation of sodium dodecyl sulfateinsoluble, Alz-50-reactive polymers of tau. J. Neurochem 1993;61:1159-1162. [PubMed: 8103081]

77. Miller ML, Johnson GVW. Transglutaminase cross-linking of the tau protein. J. Neurochem 1995;65:1760-1770. [PubMed: 7561874]

78. Murthy SN, Wilson JH, Lukas TJ, et al. Cross-linking sites of the human tau protein, probed by reactions with human transglutaminase. J. Neurochem 1998;71:2607-2614. [PubMed: 9832162]

79. Wang DS, Dickson DW, Malter JS. Tissue Transglutaminase, protein cross-linking and Alzheimer's disease: review and views. Int. J. Clin. Exp. Pathol 2008;1:5-18. [PubMed: 18784819]

80. Junn E, Ronchetti RD, Quezado MM, et al. Tissue transglutaminase-induced aggregation of $\alpha$ synuclein: implications for Lewy body formation in Parkinson's disease and dementia with Lewy bodies. Proc. Natl Acad. Sci. USA 2003;100:2047-2052. [PubMed: 12576551]

81. Schmid AW, Chiappe D, Pignat V, et al. Dissecting the mechanisms of tissue transglutaminaseinduced cross-linking of $\alpha$-synuclein: implications for the pathogenesis of Parkinson's disease. J. Biol. Chem. 2009 DOI: 10.1074/jbc.M809067200. (Epub ahead of print).

82. Segers-Nolten IM, Wilhelmus MM, Veldhuis G, et al. Tissue transglutaminase modulates $\alpha$-synuclein oligomerization. Protein Sci 2008;17:1395-1402. [PubMed: 18505736]

83. Steinert PM, Kim SY, Chung SI, et al. The transglutaminase 1 enzyme is variably acylated by myristate and palmitate during differentiation in epidermal keratinocytes. J. Biol. Chem 1996;271:26242-26250. [PubMed: 8824274]

84. Kim SY, Chung SI, Steinert PM. Highly active soluble processed forms of the transglutaminase 1 enzyme in epidermal keratinocytes. J. Biol. Chem 1995;270:18026-18035. [PubMed: 7629111]

85. Nemes Z, Steinert PM. Bricks and mortar of the epidermal barrier. Exp. Mol. Med 1999;31:5-19. [PubMed: 10231017]

86. Busche MA, Eichhoff G, Adelsberger H, et al. Clusters of hyperactive neurons near amyloid plaques in a mouse model of Alzheimer's disease. Science 2008;321:1686-1689. [PubMed: 18802001]

87. Tandon A, Fraser P. The presenilins. Genome Biol 2002;3:3014.

88. Tu H, Nelson O, Bezprozvanny A, et al. Presenilins form $\mathrm{ER} \mathrm{Ca}^{2+}$ leak channels, a function disrupted by familial Alzheimer's disease-linked mutations. Cell 2006;126:981-993. [PubMed: 16959576] 
89. Nelson O, Tu H, Lei T, et al. Familial Alzheimer disease-linked mutations specifically disrupt $\mathrm{Ca}^{2}$ ${ }^{+}$leak function of presenilin 1. J. Clin. Invest 2007;117:1230-1239. [PubMed: 17431506]

90. Stutzmann GE, Caccamo A, LaFerla FM, et al. Dysregulated IP3 signaling in cortical neurons of knock-in mice expressing an Alzheimer's-linked mutation in presenilin1 results in exaggerated $\mathrm{Ca}^{2}$ + signals and altered membrane excitability. J. Neurosci 2004;24:508-513. [PubMed: 14724250]

91. Stutzmann GE, Smith I, Caccamo A, et al. Enhanced ryanodine receptor recruitment contributes to $\mathrm{Ca}^{2+}$ disruptions in young, adult, and aged Alzheimer's disease mice. J. Neurosci 2006;26:51805189. [PubMed: 16687509]

92. Thibault O, Gant JC, Landfield PW. Expansion of the calcium hypothesis of brain aging and Alzheimer's disease: minding the store. Aging Cell 2007;6:307-317. [PubMed: 17465978]

93. Wang SQ, Song LS, Lakatta EG, et al. $\mathrm{Ca}^{2+}$ signalling between single L-type $\mathrm{Ca}^{2+}$ channels and ryanodine receptors in heart cells. Nature 2001;410:592-596. [PubMed: 11279498]

94. Oddo S, Caccamo A, Shepherd JD, et al. Triple-transgenic model of Alzheimer's disease with plaques and tangles: intracellular $A \beta$ and synaptic dysfunction. Neuron 2003;39:409-421. [PubMed: 12895417]

95. Gibson GE, Zhang H, Toral-Barza L, et al. Calcium stores in cultured fibroblasts and their changes with Alzheimer's disease. Biochim. Biophys. Acta 1996;1316:71-77. [PubMed: 8672553]

96. Gusella JF, MacDonald ME. Hunting for Huntington's disease. Mol. Genet. Med 1993;3:139-158. [PubMed: 8220162]

97. Stine OC, Pleasant N, Franz ML, et al. Correlation between the onset age of Huntington's disease and length of the trinucleotide repeat in IT-15. Hum. Mol. Genet 1993;2:1547-1549. [PubMed: 8268907]

98. Brandt J, Bylsma FW, Gross R, et al. Trinucleotide repeat length and clinical progression in Huntington's disease. Neurology 1996;46:527-531. [PubMed: 8614526]

99. DiFiglia M, Sapp E, Chase K, et al. Huntingtin is a cytoplasmic protein associated with vesicles in human and rat brain neurons. Neuron 1995;14:1075-1081. [PubMed: 7748555]

100. Chen S, Berthelier V, Yang W, et al. Polyglutamine aggregation behavior in vitro supports a recruitment mechanism of cytotoxicity. J. Mol. Biol 2001;311:173-182. [PubMed: 11469866]

101 . Green H. Human genetic diseases due to codon reiteration: relationship to an evolutionary mechanism. Cell 1993;74:955-956. [PubMed: 8104707] [ of interestFirst suggestion that expanded Qn domains may be good TG substrates and thereby contribute to HD pathology.]

102. Kahlem P, Terré C, Green H, et al. Peptides containing glutamine repeats as substrates for transglutaminase-catalyzed cross-linking: relevance to diseases of the nervous system. Proc. Natl Acad. Sci. USA 1996;93:14580-14585. [PubMed: 8962095]

103. Kahlem P, Green H, Djian P. Transglutaminase action imitates Huntington's disease: selective polymerization of Huntingtin containing expanded polyglutamine. Mol. Cell 1998;1:595-601. [PubMed: 9660943]

104. Karpuj MV, Garren H, Slunt H, et al. Transglutaminase aggregates huntingtin into nonamyloidogenic polymers, and its enzymatic activity increases in Huntington's disease brain nuclei. Proc. Natl Acad. Sci. USA 1999;96:7388-7393. [PubMed: 10377424]

105. Cooper AJL, Jeitner TM, Gentile V, et al. Cross linking of polyglutamine domains catalyzed by tissue transglutaminase is greatly favored with pathological-length repeats: does transglutaminase activity play a role in (CAG) n/Qn-expansion diseases? Neurochem. Int 2002;40:53-67. [PubMed: 11738472]

106. Zainelli GM, Dudek NL, Ross CA, et al. Mutant huntingtin protein: a substrate for transglutaminase 1, 2, and 3. J. Neuropathol. Exp. Neurol 2005;64:58-65. [PubMed: 15715085] [ of interestDemonstration that mutant $h t t$ is substrate of three TGs in human brain.]

107. Zainelli GM, Ross CA, Troncoso JC, et al. Transglutaminase cross-links in intranuclear inclusions in Huntington disease. J. Neuropathol. Exp. Neurol 2003;62:14-24. [PubMed: 12528814]

108. Lesort M, Chun W, Johnson GVW, et al. Tissue transglutaminase is increased in Huntington's disease brain. J. Neurochem 1999;73:2018-2027. [PubMed: 10537061]

109. Lee J, Kim YS, Choi DH. Transglutaminase 2 induces nuclear factor- $\kappa B$ activation via a novel pathway in BV-2 microglia. J. Biol. Chem 2004;279:53725-53735. [PubMed: 15471861] 
110. Zhang H, Das S, Li QZ, et al. Elucidating a normal function of huntingtin by functional and microarray analysis of huntingtin-null mouse embryonic fibroblasts. BMC Neurosci 2008;9:38. [PubMed: 18412970]

111. Tang TS, Tu H, Chan EY, et al. Huntingtin and huntingtin-associated protein 1 influence neuronal calcium signaling mediated by inositol-(1,4,5) triphosphate receptor type 1 . Neuron 2003;39:227239. [PubMed: 12873381]

112. Cepeda C, Ariano MA, Calvert CR, et al. NMDA receptor function in mouse models of Huntington disease. J. Neurosci Res 2001;66:525-539. [PubMed: 11746372]

113. Zeron MM, Hansson $\mathrm{O}$, Chen $\mathrm{N}$, et al. Increased sensitivity to $N$-methyl-d-aspartate receptormediated excitotoxicity in a mouse model of Huntington's disease. Neuron 2002;33:849-860. [PubMed: 11906693]

114. Tang TS, Chen X, Liu J, et al. Dopaminergic signaling and striatal neurodegeneration in Huntington's disease. J. Neurosci 2007;27:7899-7910. [PubMed: 17652581]

115. Hodgson JG, Agopyan N, Gutekunst CA, et al. A YAC mouse model for Huntington's disease with full-length mutant huntingtin, cytoplasmic toxicity, and selective striatal neurodegeneration. Neuron 1999;23:181-192. [PubMed: 10402204]

116. Romero E, Cha GH, Verstreken P, et al. Suppression of neurodegeneration and increased neurotransmission caused by expanded full-length huntingtin accumulating in the cytoplasm. Neuron 2008;57:27-40. [PubMed: 18184562]

117. Panov AV, Lund S, Greenamyre JT. $\mathrm{Ca}^{2+}$-induced permeability transition in human lymphoblastoid cell mitochondria from normal and Huntington's disease individuals. Mol. Cell Biochem 2005;269:143-152. [PubMed: 15786727]

118. Panov AV, Gutekunst CA, Leavitt BR, et al. Early mitochondrial calcium defects in Huntington's disease are a direct effect of polyglutamines. Nat. Neurosci 2005;5:731-736. [PubMed: 12089530]

119. Milakovic T, Quintanilla RA, Johnson GVW. Mutant huntingtin expression induces mitochondrial calcium handling defects in clonal striatal cells: functional consequences. J. Biol. Chem 2006;281:34785-34795. [PubMed: 16973623]

120. Lim D, Fedrizzi L, Tartari M, et al. Calcium homeostasis and mitochondrial dysfunction in striatal neurons of Huntington disease. J. Biol. Chem 2008;283:5780-5789. [PubMed: 18156184]

121. Puszkin EG, Raghuraman V. Catalytic properties of a calmodulin-regulated transglutaminase from human platelet and chicken gizzard. J. Biol. Chem 1985;260:16012-16020. [PubMed: 2866189]

122. Billett HH, Puszkin EG. The red cell membrane contains calmodulin-regulated crosslinking and proteolytic activity. Hematol. Pathol 1991;5:185-193. [PubMed: 1686607]

123. Zainelli GM, Ross CA, Troncoso JC, et al. Calmodulin regulates transglutaminase 2 cross-linking of Huntingtin. J. Neurosci 2004;24:1954-1961. [PubMed: 14985437]

124. Dudek NL, Dai Y, Muma NA. Protective effects of interrupting the binding of calmodulin to mutant huntingtin. J. Neuropathol. Exp. Neurol 2008;67:355-365. [PubMed: 18379433]

125. Dudek NL, Dai Y, Muma NA. Neuroprotective effects of calmodulin peptide 76-121aa: disruption of calmodulin binding to mutant huntingtin. Brain Pathol. 2008 DOI: 10.1111/j.1750 -3639.2008.00258.x. (In Press).

126m. Mastroberardino PG, Iannicola C, Nardacci R, et al. 'Tissue' transglutaminase ablation reduces neuronal death and prolongs survival in a mouse model of Huntington's disease. Cell Death Differ 2002;9:873-880. [PubMed: 12181738] [ $\mathbf{m}$ of considerable interestCompelling evidence that TG 2 contributes to HD pathology.]

127. Liu P, Gupta N, Jing Y, et al. Age-related changes in polyamines in memory-associated brain structures in rats. Neuroscience 2008;155:789-796. [PubMed: 18621105]

128. Kim SY, Jeitner TM, Steinert PM. Transglutaminases in disease. Neurochem. Int 2002;40:85-103. [PubMed: 11738475]

129. Muma NA. Transglutaminase is linked to neurodegenerative diseases. J. Neuropathol. Exp. Neurol 2007;66:258-263. [PubMed: 17413316] [ of interestRecent review of TGs in neurodegeneration.]

130. Lees AJ. The Parkinson chimera. Neurology 2009;72(Suppl 7):S2-S11. [PubMed: 19221309]

131. Mezey E, Dehejia A, Harta G, et al. $\alpha$-synuclein in neurodegenerative disorders: murderer or accomplice? Nat. Med 1998;4:755-757. [PubMed: 9662355] 
132. Spillantini MG, Schmidt ML, Lee VM, et al. $\alpha$-synuclein in Lewy bodies. Nature 1997;388:839840. [PubMed: 9278044]

133. Arima K, Uéda K, Sunohara N, et al. Immunoelectron-microscopic demonstration of NACP/ $\alpha$ synuclein-epitopes on the filamentous component of Lewy bodies in Parkinson's disease and in dementia with Lewy bodies. Brain Res 1998;808:93-100. [PubMed: 9795161]

134. Wirths O, Weickert S, Majtenyi K, et al. Lewy body variant of Alzheimer's disease: $\alpha$-synuclein in dystrophic neurites of A $\beta$ plaques. Neuroreport 2000;11:3737-3741. [PubMed: 11117482]

135. Emadi S, Kasturirangan S, Wang MS, et al. Detecting morphologically distinct oligomeric forms of $\alpha$-synuclein. J. Biol. Chem. 2009 DOI: 10.1074/jbc.M806559200. (Epub ahead of print).

136. Kragh CL, Lund LB, Febbraro F, et al. $\alpha$-Synuclein aggregation and Ser129 phosphorylation dependent cell death in oligodendroglial cells. J. Biol. Chem. 2009 DOI: 10.1074/jbc.M809671200. (Epub ahead of print).

137. Masliah E, Rockenstein E, Veinbergs I, et al. Dopaminergic loss and inclusion body formation in $\alpha$-synuclein mice: implications for neurodegenerative disorders. Science 2000;287:1265-1269. [PubMed: 10678833]

138. Polymeropoulos MH, Lavedan C, Leroy E, et al. Mutation in the $\alpha$-synuclein gene identified in families with Parkinson's disease. Science 1997;276:2045-2047. [PubMed: 9197268]

139. Krüger R, Kuhn W, Müller T, et al. Ala30Pro mutation in the gene encoding $\alpha$-synuclein in Parkinson's disease. Nat. Genet 1998;18:106-108. [PubMed: 9462735]

140. Uversky VN. $\alpha$-synuclein misfolding and neurodegenerative diseases. Curr. Protein Pept. Sci 2008;9:507-540. [PubMed: 18855701]

141. Andringa G, Lam KY, Chegary M, Wang X, et al. Tissue transglutaminase catalyzes the formation of $\alpha$-synuclein crosslinks in Parkinson's disease. FASEB J 2004;18:932-934. [PubMed: 15001552]

142. Bennett EJ, Shaler TA, Woodman B, et al. Global changes to the ubiquitin system in Huntington's disease. Nature 2007;448:704-708. [PubMed: 17687326]

143. Wang J, Wang CE, Orr A, et al. Impaired ubiquitin-proteasome system activity in the synapses of Huntington's disease mice. J. Cell Biol 2008;180:1177-1189. [PubMed: 18362179]

144. Mandrusiak LM, Beitel LK, Wang X, et al. Transglutaminase potentiates ligand-dependent proteasome dysfunction induced by polyglutamine-expanded androgen receptor. Hum. Mol. Genet 2003;12:1497-1506. [PubMed: 12812978]

145. Surmeier DJ. Calcium, ageing, and neuronal vulnerability in Parkinson's disease. Lancet Neurol 2007;6:933-938. [PubMed: 17884683]

146. Ibáñez-Sandoval O, Carrillo-Reid L, Galarraga E, et al. Bursting in substantia nigra pars reticulata neurons in vitro: possible relevance for Parkinson disease. J. Neurophysiol 2007;98:2311-2323. [PubMed: 17715194]

147. Choi YM, Kim SH, Uhm DY, et al. Glutamate-mediated $\left[\mathrm{Ca}^{2+}\right] \mathrm{c}$ dynamics in spontaneously firing dopamine neurons of the rat substantia nigra pars compacta. J. Cell Sci 2003;116:2665-2675. [PubMed: 12746490]

148. McMahon A, Wong BS, Iacopino AM, et al. Calbindin-D28k buffers intracellular calcium and promotes resistance to degeneration in PC12 cells. Brain Res. Mol. Brain Res 1998;54:56-63. [PubMed: 9526044]

149. Houghton DJ, Litvan I. Unraveling progressive supranuclear palsy: from the bedside back to the bench. Parkinsonism Relat. Disord 2007;13(Suppl 3):S336-S340. [PubMed: 18267261]

150. Zemaitaitis MO, Lee JM, Troncoso JC, et al. Transglutaminase-induced cross-linking of tau proteins in progressive supranuclear palsy. J. Neuropathol. Exp. Neurol 2000;59:983-989. [PubMed: 11089576]

151. Zemaitaitis MO, Kim SY, Halverson RA, et al. Transglutaminase activity, protein, and mRNA expression are increased in progressive supranuclear palsy. J. Neuropathol. Exp. Neurol 2003;62:173-184. [PubMed: 12578227]

152. Albers DS, Augood SJ. New insights into progressive supranuclear palsy. Trends Neurosci 2001;24:347-353. [PubMed: 11356507]

153. Walther DJ, Peter JU, Winter S, et al. Serotonylation of small GTPases is a signal transduction pathway that triggers platelet $\alpha$-granule release. Cell 2003;115:851-862. [PubMed: 14697203] 
154. Dai Y, Dudek NL, Patel TB, et al. Transglutaminase-catalyzed transamidation: a novel mechanism for Rac1 activation by 5-hydroxytryptamine2A receptor stimulation. J. Pharmacol. Exp. Ther 2008;326:153-162. [PubMed: 18400843]

155. Lorand L, Conrad SM. Transglutaminases. Mol. Cell Biochem 1984;58:9-35. [PubMed: 6143256]

156. Jeitner TM, Delikatny EJ, Ahlqvist J, et al. Mechanism for the inhibition of transglutaminase 2 by cystamine. Biochem. Pharmacol 2005;69:961-970. [PubMed: 15748707]

157. Karpuj MV, Becher MW, Springer JE, et al. Prolonged survival and decreased abnormal movements in transgenic model of Huntington disease, with administration of the transglutaminase inhibitor cystamine. Nat. Med 2002;8:143-149. [PubMed: 11821898]

158. Van Raamsdonk JM, Pearson J, Bailey CDC, et al. Cystamine treatment is neuroprotective in the YAC128 mouse model of Huntington disease. J. Neurochem 2005;95:210-220. [PubMed: 16181425]

159. Stack EC, Ferro JL, Kim J, et al. Therapeutic attenuation of mitochondrial dysfunction and oxidative stress in neurotoxin models of Parkinson's disease. Biochim. Biophys. Acta 2008;1782:151-162. [PubMed: 18206128]

160. Fox JH, Barber DS, Singh B, et al. Cystamine increases 1-cysteine levels in Huntington's disease transgenic mouse brain and in a PC12 model of polyglutamine aggregation. J. Neurochem 2004;91:413-422. [PubMed: 15447674]

161. Pinto JT, Van Raamsdonk JM, Leavitt BR, et al. Treatment of YAC128 mice and their wild-type littermates with cystamine does not lead to its accumulation in plasma or brain: implications for the treatment of Huntington disease. J. Neurochem 2005;94:1087-1101. [PubMed: 15992377]

162. Borrell-Pagès M, Canals JM, Cordelières FP, et al. Cystamine and cysteamine increase brain levels of BDNF in Huntington disease via HSJ1b and transglutaminase. J. Clin. Invest 2006;116:14101424. [PubMed: 16604191]

163. Jeitner TM, Pinto JT, Kranikov BF, et al. Transglutaminases and neurodegeneration. J. Neurochem 2009;109(Suppl 1):160-166. [PubMed: 19393023]

164. Lesort M, Lee M, Tucholski J, et al. Cystamine inhibits caspase activity. Implications for the treatment of polyglutamine disorders. J. Biol. Chem 2003;278:3825-3830. [PubMed: 12458211]

165. Bailey CDC, Johnson GVW. The protective effects of cystamine in the R6/2 Huntington's disease mouse involves mechanisms other than the inhibition of tissue transglutaminase. Neurobiol. Aging 2006;27:871-879. [PubMed: 15896882]

166. Goldstone SD, Fragonas JC, Jeitner TM, et al. Transcription factors as targets for oxidative signalling during lymphocyte activation. Biochim. Biophys. Acta 1995;1263:114-122. [PubMed: 7640301]

167. Medvedev A, Saunders NA, Matsuura H, et al. Regulation of the transglutaminase I gene. Identification of DNA elements involved in its transcriptional control in tracheobronchial epithelial cells. J. Biol. Chem 1999;274:3887-3896. [PubMed: 9920944]

168. Lorand L, Rule NG, Ong HH, et al. Amine specificity in transpeptidation. Inhibition of fibrin crosslinking. Biochemistry 1968;7:1214-1223. [PubMed: 5690562]

169. Curtis CG, Brown KL, Credo RB, et al. Calcium-dependent unmasking of active center cysteine during activation of fibrin stabilizing factor. Biochemistry 1974;13:3774-3780. [PubMed: 4859234]

170. Gross M, Whetzel NK, Folk JE. Alkyl isocyanates as active site-directed inactivators of guinea pig liver transglutaminase. J. Biol. Chem 1975;250:7693-7699. [PubMed: 240837]

171. Lee KN, Fésüs L, Yancey ST, et al. Development of selective inhibitors of transglutaminase. Phenylthiourea derivatives. J. Biol. Chem 1985;260:14689-14694. [PubMed: 2865262]

172. Lee KN, Chung SI, Girard JE, et al. Evaluation of phenylthiourea derivatives as inhibitors of transglutaminase-catalyzed reaction in Chinese hamster ovary cells. Biochim. Biophys. Acta 1988;972:120-130. [PubMed: 2903774]

173. Auger M, McDermott AE, Robinson V, et al. Solid-state carbon-13 NMR study of a transglutaminase-inhibitor adduct. Biochemistry 1993;32:3930-3934. [PubMed: 8097108]

174. Choi K, Siegel M, Piper JL, et al. Chemistry and biology of dihydroisoxazole derivatives: selective inhibitors of human transglutaminase 2. Chem. Biol 2005;12:469-475. [PubMed: 15850984]

175. Watts RE, Siegel M, Khosla C. Structure-activity relationship analysis of the selective inhibition of transglutaminase 2 by dihydroisoxazoles. J. Med. Chem 2009;49:7493-7501. [PubMed: 17149878] 
176. Killackey JJ, Bonaventura BJ, Castelhano AL, et al. A new class of mechanism-based inhibitors of transglutaminase enzymes inhibits the formation of cross-linked envelopes by human malignant keratinocytes. Mol. Pharmacol 1989;35:701-706. [PubMed: 2471055]

177. Pliura DH, Bonaventura BJ, Pauls HW, et al. Irreversible inhibition of transglutaminases by sulfonium methylketones: optimization of specificity and potency with $\Omega$-aminoacyl spacers. Enzyme Inhib 1992;6:181-194.

178. Freund KF, Doshi KP, Gaul SL, et al. Transglutaminase inhibition by 2-[(2-oxopropyl)thio] imidazolium derivatives: mechanism of factor XIIIa inactivation. Biochemistry 1994;33:10109_ 10119. [PubMed: 7914744]

179. Marrano C, de Macédo P, Keillor JW. Evaluation of novel dipeptide-bound $\alpha, \beta$-unsaturated amides and epoxides as irreversible inhibitors of guinea pig liver transglutaminase. Bioorgan. Med. Chem 2001;9:1923-1928.

180. Marrano C, de Macédo P, Gagnon P, et al. Synthesis and evaluation of novel dipeptide-bound 1,2,4thiadiazoles as irreversible inhibitors of guinea pig liver transglutaminase. Bioorgan. Med. Chem 2001;9:3231-3241.

181. de Macédo P, Marrano C, Keillor JW. Synthesis of dipeptide-bound epoxides and $\alpha, \beta$-unsaturated amides as potential irreversible transglutaminase inhibitors. Bioorgan. Med. Chem 2002;10:355360.

182. Case A, Ni J, Yeh LA, et al. Development of a mechanism-based assay for tissue transglutaminase - results of a high-throughput screen and discovery of inhibitors. Anal. Biochem 2005;338:237244. [PubMed: 15745743]

183. Case A, Stein RL. Kinetic analysis of the interaction of tissue transglutaminase with a nonpeptide slow-binding inhibitor. Biochemistry 2007;46:1106-1115. [PubMed: 17240993]

184. Duval E, Case A, Stein RL, et al. Structure-activity relationship study of novel tissue transglutaminase inhibitors. Bioorg. Med. Lett 2005;15:185-189.

185. Lai T-S, Liu Y, Tucker T, et al. Identification of chemical inhibitors to human tissue transglutaminase by screening existing drug libraries. Chem. Biol 2008;15:969-978. [PubMed: 18804034]

186. Sohn J, Kim TI, Yoon YH, et al. Novel transglutaminase inhibitors reverse the inflammation of allergic conjunctivitis. J. Clin. Invest 2003;111:121-128. [PubMed: 12511595]

187. McConoughey, SJ.; Chavez, JC.; Cooper, AJL., et al. Release of transcriptional repression created by transglutaminase is protective in mutant huntingtin expressing neurons.. Presented at: Annual Meeting of the Society for Neuroscience.; San Diego, CA, USA. 3-7 November 2007;

188. McConoughey, SJ.; Nietsetskaya, Z.; Karpisheva, K., et al. Transglutaminase 2 inhibition ameliorates transcriptional dysregulation in Huntington disease.. Presented at: Annual Meeting of the Society for Neuroscience.; Washington, DC, USA. 15-19 November 2008;

189. Gines S, Seong IS, Fossale E, et al. Specific progressive cAMP reduction implicates energy deficit in presymptomatic Huntington's disease knock-in mice. Hum. Mol. Gentet 2003;12:497-508.

190m. Yuan L, Choi K, Khosla C. Tissue transglutaminase 2 inhibition promotes cell death and chemosensitivity in glioblastomas. Mol. Cancer Ther 2005;4:1293-1302. [PubMed: 16170020] [ of interestImportant demonstration of the possibility of using TG inhibitors as therapeutics.]

191. Yuan L, Siegel M, Choi K, et al. Transglutaminase 2 inhibitor, KCC009, disrupts fibronectin assembly in the extracellular matrix and sensitizes orthoptic glioblastomas to chemotherapy. Oncogene 2007;26:2563-2573. [PubMed: 17099729] 


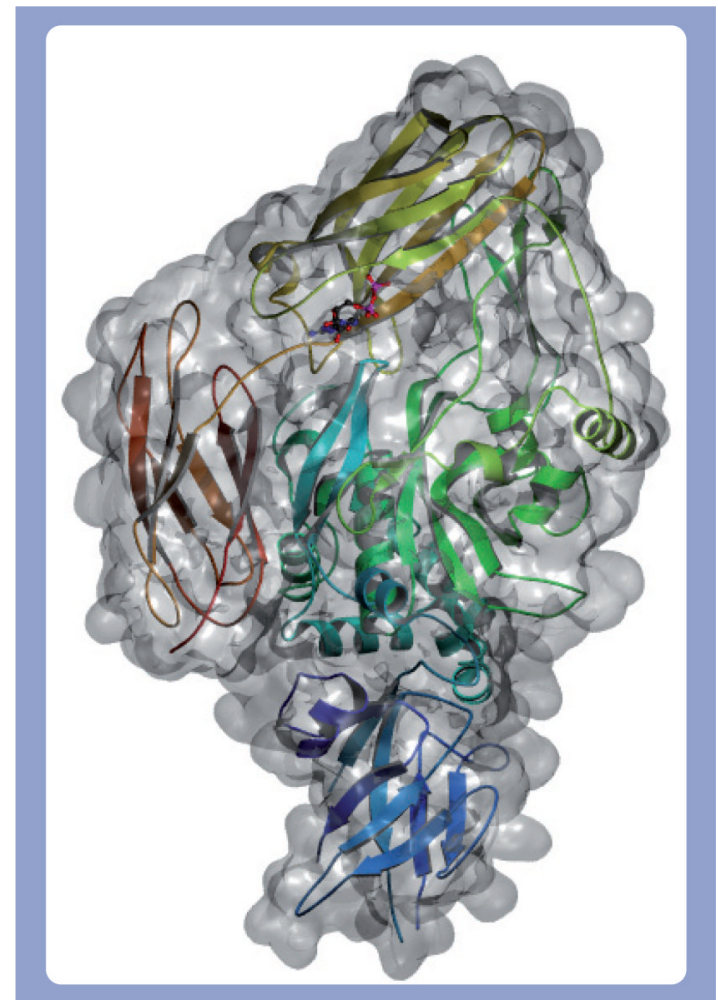

Figure 1. Closed state of TG 2

The secondary structure of the closed form of TG 2 (PDB 1KV3) is rendered as a ribbon inside the molecular surface of the protein with an associated GDP depicted in a ball-and-stick configuration. 


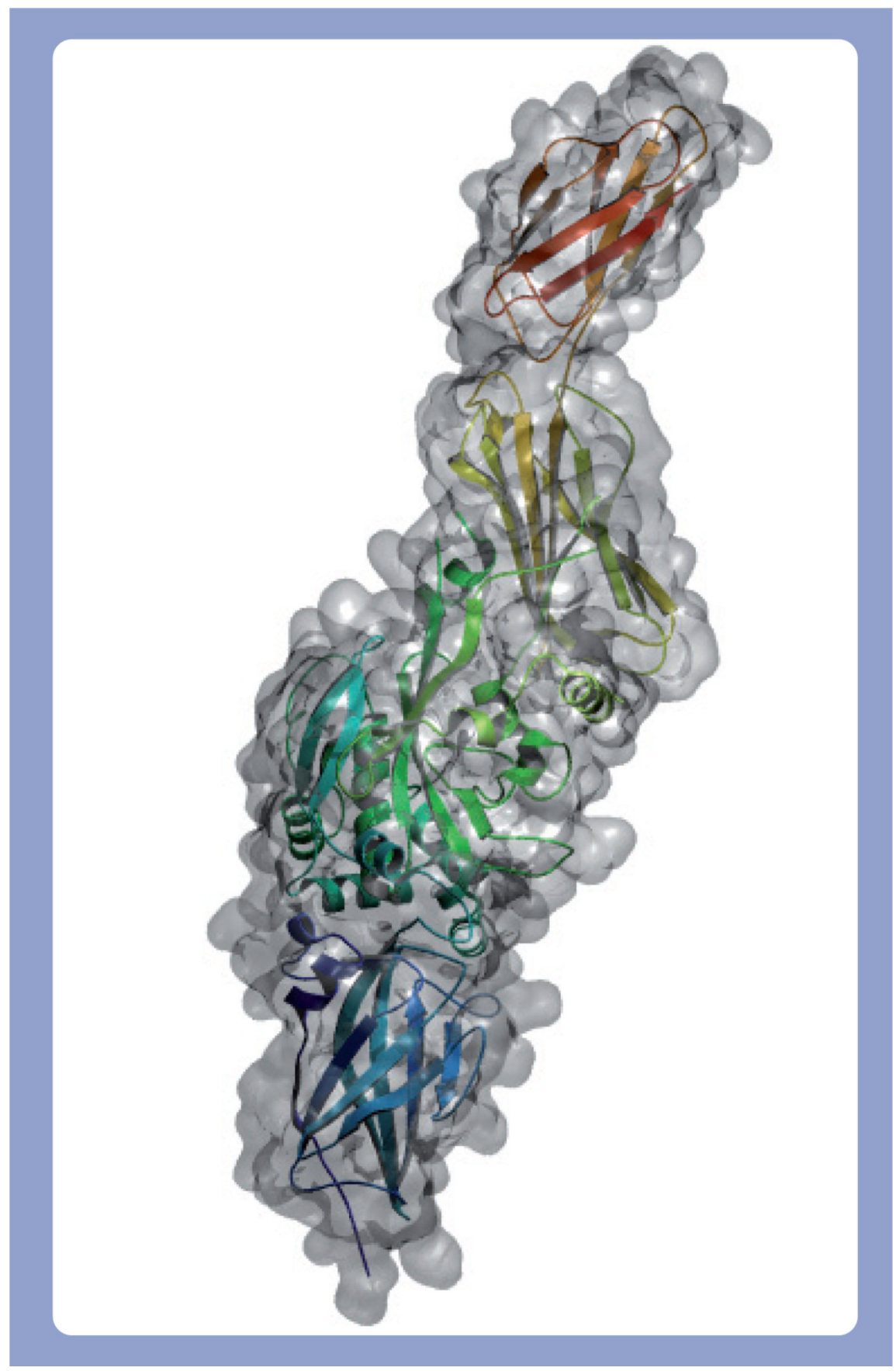

Figure 2. Active state of TG 2 with exposed active site

The secondary structure of the unfolded active form of TG 2 (PDB 2Q3Z) is rendered as a ribbon inside the molecular surface of the protein. 


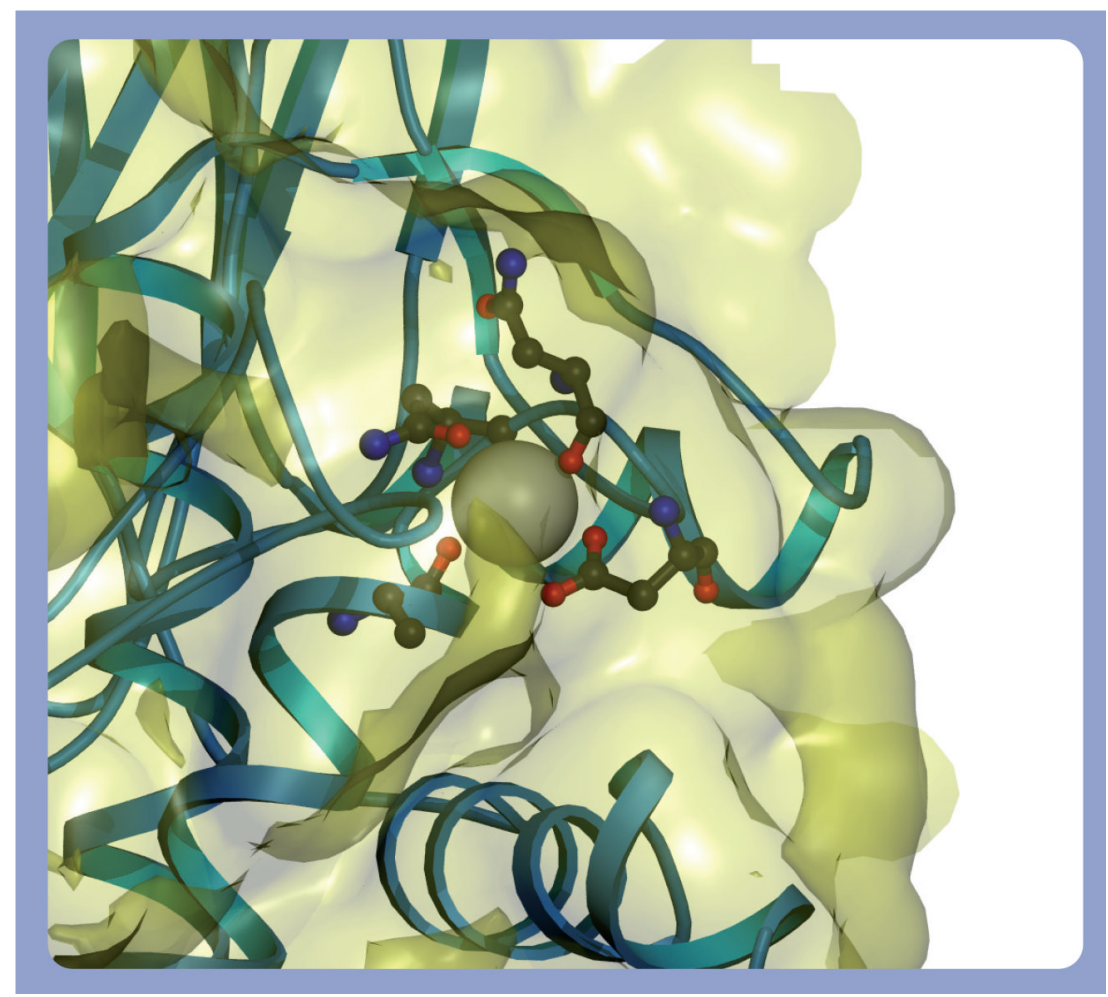

Figure 3. Calcium-binding site 1 in TG 3

The coordinating residues for the calcium bound to site 1 of TG 3 (PDB 1L9N) are rendered as a ribbon, and residues $\mathrm{Ala}^{221}, \mathrm{Asn}^{224}, \mathrm{Asn}^{226}$ and $\mathrm{Asp}_{228}$ are shown in a ball-and-stick configuration around the calcium. The molecular surface of the protein is shown in yellow. It should be noted that the calcium at this site is almost fully enveloped inside the surface of the protein. 


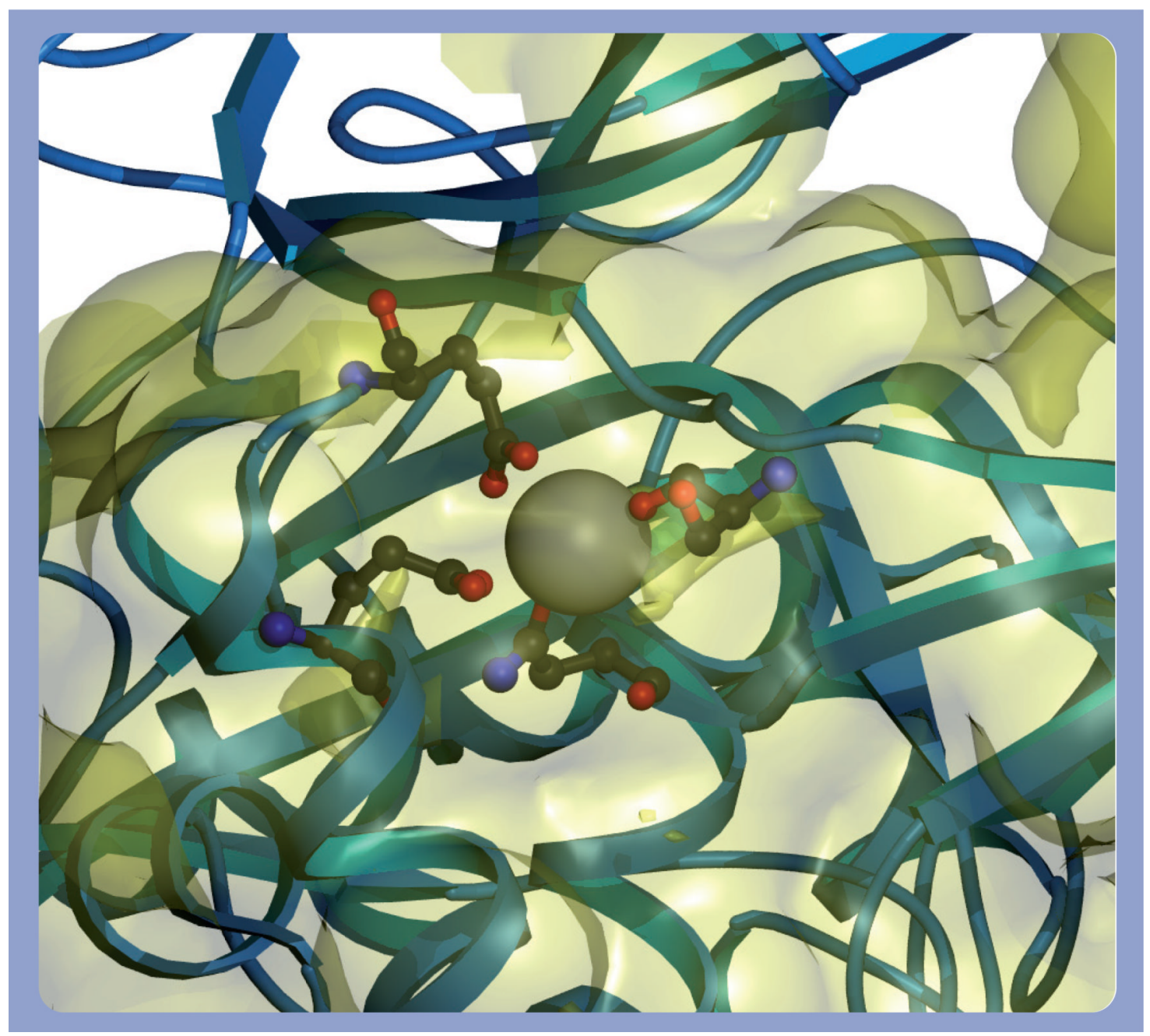

Figure 4. Calcium-binding site 2 in TG 3

The coordinating residues for the calcium bound to site 2 of TG 3 in both the calcium bound (PDB 1L9N) and calcium free (PDB 1L9M) are shown. The backbone of the bound state is rendered in blue and the free state is rendered in green, as are the atoms with the calcium rendered as in CPK. The residues involved are $\mathrm{Asn}^{393}, \mathrm{Ser}^{415}, \mathrm{Glu}^{443}$ and $\mathrm{Glu}^{448}$. It should be noted that there is significant motion of $\mathrm{Asn}^{393}$ and $\mathrm{Glu}^{443}$ upon calcium binding. 


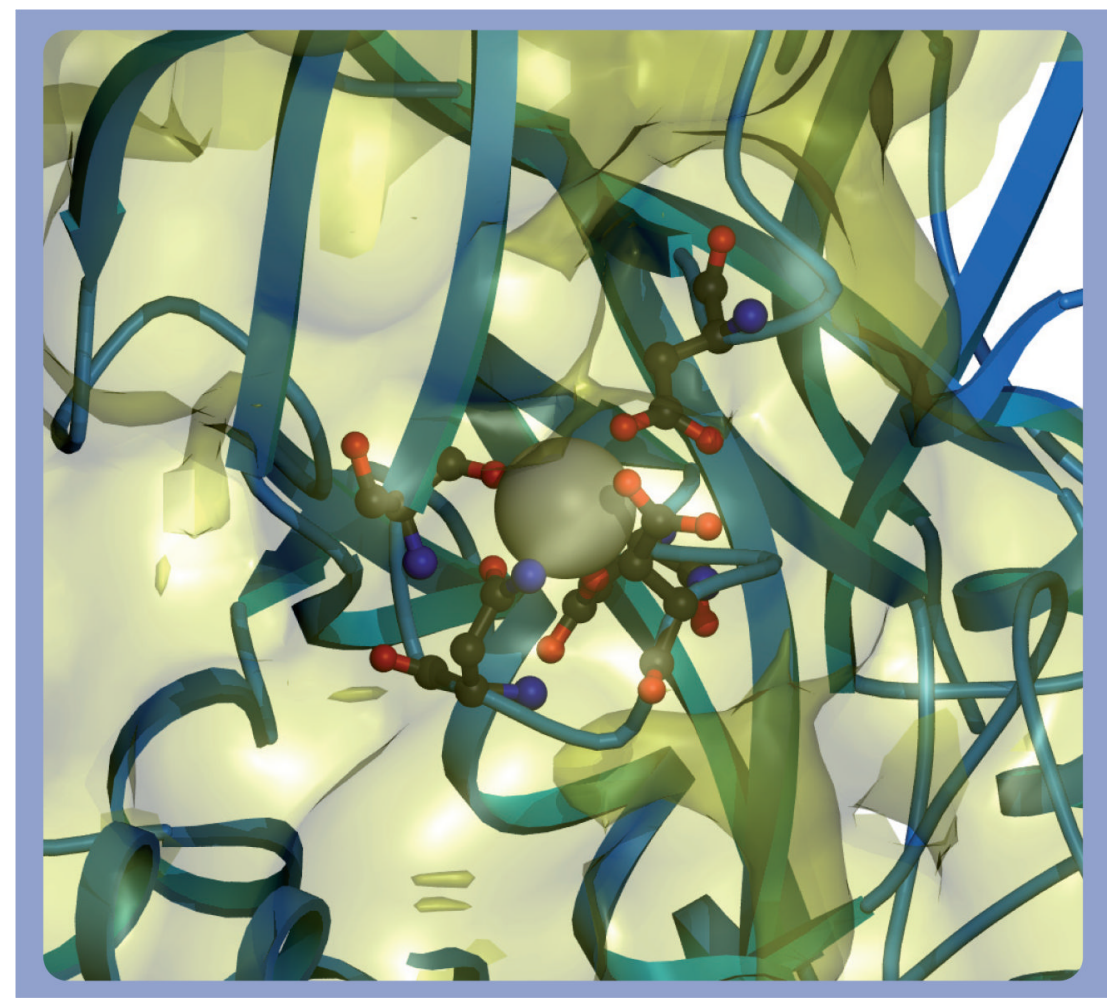

Figure 5. Calcium-binding site 3 in TG 3

The coordinating residues for the calcium bound to site 3 of TG 3 in both the calcium-bound (PDB 1L9N) and calcium-free state (PDB 1L9M) are shown. The backbone of the bound state is rendered in blue and the free state is rendered in green, as are the atoms with the calcium rendered as in CPK. The residues involved are $\mathrm{Asp}^{301}, \mathrm{Asp}^{303}, \mathrm{Asn}^{305}, \mathrm{Ser}^{307}$ and $\mathrm{Asp}^{324}$. Of note, there is significant motion of $\mathrm{Asp}^{324}$ in this binding site, which in the free state is significantly displaced from its position in the bound state. 